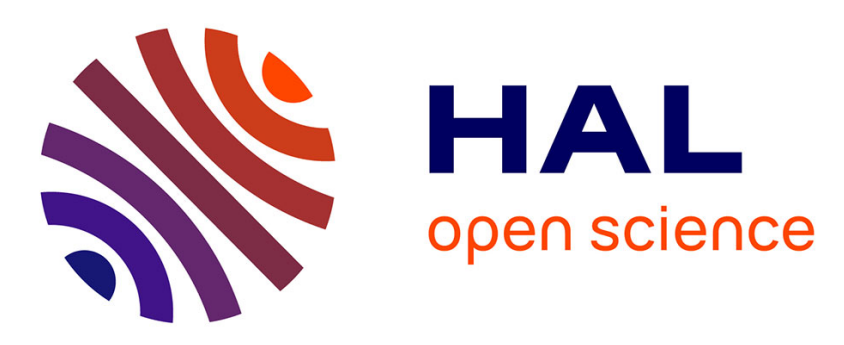

\title{
Activated carbon xerogels derived from phenolic oil: Basic catalysis synthesis and electrochemical performances
}

Angela Sanchez-Sanchez, Maria Teresa Izquierdo, Sandrine Mathieu, Ghouti Medjahdi, Vanessa Fierro, Alain Celzard

\section{To cite this version:}

Angela Sanchez-Sanchez, Maria Teresa Izquierdo, Sandrine Mathieu, Ghouti Medjahdi, Vanessa Fierro, et al.. Activated carbon xerogels derived from phenolic oil: Basic catalysis synthesis and electrochemical performances. Fuel Processing Technology, 2020, 205, pp.106427. 10.1016/j.fuproc.2020.106427 . hal-02898249

\section{HAL Id: hal-02898249 \\ https://hal.univ-lorraine.fr/hal-02898249}

Submitted on 13 Jul 2020

HAL is a multi-disciplinary open access archive for the deposit and dissemination of scientific research documents, whether they are published or not. The documents may come from teaching and research institutions in France or abroad, or from public or private research centers.
L'archive ouverte pluridisciplinaire HAL, est destinée au dépôt et à la diffusion de documents scientifiques de niveau recherche, publiés ou non, émanant des établissements d'enseignement et de recherche français ou étrangers, des laboratoires publics ou privés. 
Activated carbon xerogels derived from phenolic oil: basic catalysis synthesis and electrochemical performances

Angela Sanchez-Sanchez ${ }^{a *}$, Maria Teresa Izquierdo ${ }^{b}$, Sandrine Mathieu ${ }^{c}$, Ghouti Medjahdi $^{c}$, Vanessa Fierro ${ }^{a} *$ and Alain Celzard ${ }^{a}$

a Université de Lorraine, CNRS, IJL, F-88000 Epinal, France.

${ }^{\mathrm{b}}$ Instituto de Carboquimica, ICB-CSIC, Miguel Luesma Castan, 4, 50018 Zaragoza, Spain.

c Université de Lorraine, CNRS, IJL, F-54000 Nancy, France.

E-mail: *A. Sanchez-Sanchez: angela.sanchez-sanchez@univ-lorraine.fr. *Vanessa Fierro: vanessa.fierro@univ-lorraine.fr 


\section{ABSTRACT}

The competitiveness of European coal tar distillation plants could be improved by the revaluation of coal-derived liquids and rejects such as phenolic oils, which currently lack highend applications. In this study, carbon gels were successfully prepared for the first time from phenolic oil by base-catalysed sol-gel polymerisation, by taking advantage of all the major components of phenolic oil rather than the pure, single-component phenolic precursors that are normally used in sol-gel routes. To increase the feasibility of industrial applications, the organic gels were dried under subcritical conditions and the resultant xerogels were submitted to carbonisation and chemical activation in a one-step process, using different $\mathrm{KOH}$ to organic gel mass ratios. The resultant ACs were applied as supercapacitor electrodes and attained higher electrochemical performances than carbon gels previously obtained from classic precursors: high capacitance retention up to $74.9 \%$ at $12 \mathrm{~A} \mathrm{~g}^{-1}$, energy and power densities up to $7.37 \mathrm{~W} \mathrm{~h} \mathrm{~kg}^{-1}$ and $5.70 \mathrm{~kW} \mathrm{~h} \mathrm{~kg}^{-1}$, respectively, high cycling stabilities up to $94.8 \%$ after 10000 charge-discharge cycles, high rate capability of $66 \%$ under $1 \mathrm{~V} \mathrm{~s}^{-1}$ scan rate, and fast frequency response of 0.45 seconds.

Keywords: Phenolic oil, xerogel, sol-gel polymerisation, activated carbon, supercapacitor. 


\section{Introduction}

Optimal use of coal-derived liquids must be achieved to increase the viability and competitiveness of European coal tar distillation plants. To this end, it is essential to find new ways to revaluate liquids that are currently of low value and are not used in high-end applications. This is the case of creosotes, phenolic oils and waste products obtained from the purification of coal tar fractions of much higher value.

Coal tar is a highly viscous liquid obtained as a by-product of coal carbonisation, and is a complex mixture of polycyclic aromatic hydrocarbons and phenolic compounds. The distillation of coal tar leads to different fractions containing valuable products, such as naphthalene, anthracene oil or pitch, liquids such as creosotes, light oils, phenolic oils and wash oils, as well as several rejects or by-products of the purification of higher value fractions, such as naphthalene oils [1]. The most valuable fractions are widely used in the industry: naphthalene is used for the manufacture of polymers, dyes and resins; anthracene oil, to produce carbon black used as a pigment and to reinforce tires; pitch, to fabricate carbon fibres, for plastic reinforcement, and synthetic graphite, to be applied as electrode in the steel and aluminium industries [2-4]. However, valuable applications of liquids and rejects have been generally lacking, even if the latter are rich in aromatic compounds and heterocycles that can be exploited to their advantage.

Phenolic oils (POs) are naturally amenable to the synthesis of porous carbons because they are mainly composed of phenol and other aromatic compounds. Porous activated carbons have traditionally been prepared from carbonisation of coal or lignocellulosic precursors (wood, coconut shells, olive stones, rice husks, etc.), frequently followed by activation of the resulting chars to further develop their porous texture [5-8]. Porous carbon gels can be synthesised by carbonisation of dried organic gels, which are in turn obtained by sol-gel polymerisation of 
organic monomers under acidic or basic conditions [9]. The polymerisation of resorcinol with formaldehyde in aqueous medium is one of the most used routes for the production of organic gels for subsequent carbonisation [10]. However, due to the high cost of resorcinol and the expensive supercritical drying step applied in the conventional process of carbon aerogel synthesis, the corresponding market is still limited. To reduce costs, it is possible to use cheaper precursors or replace the supercritical drying step with convective drying under subcritical conditions.

Phenol has been considered a substitute for resorcinol, its polymerisation being carried out in $n$-propanol instead of water under very acidic conditions in order to solve problems related to the lower water solubility and lower reactivity of phenol with respect to resorcinol, and to facilitate the drying of organic gels [11]. It should be noted that the synthesis of carbon gels by sol-gel routes is generally based on the use of pure, single-component precursors [10-12]. The use of coal-derived POs as a substitute for pure phenol for this purpose appears a priori problematic, since components of such oils other than phenol themselves should not participate in the desired polymerisation reactions. However, it has already been observed that the partial replacement of phenol by selected chemical species leads to gels having useful characteristics. The replacement of $20 \%$ phenol with 2,4-di-tert-butylphenol shifted the porosity of the resulting carbon gels from mesoporous to macroporous, and increased their microporosity [11]. Sol-gel polycondensation of phenol, m-cresol and furfural in n-propanol under acidic conditions also allowed the synthesis of mesopore-rich carbon aerogels [13], and phenolic resins were produced from phenolic bio-oil obtained by direct liquefaction of Eastern white pine, used as a substitute for phenol at a high substitution level (75\%) [14]. Since organic gels are semisolid systems comprising solid and liquid phases, the liquid phase must be removed to form a porous backbone. Porosity is 
especially developed when drying is performed under supercritical conditions (aerogels) or by freeze-drying (cryogels) [15]. Drying under subcritical conditions (xerogels) is a much less expensive method, but normally involves partial shrinkage of the organic material and pore collapse due to capillary forces. Therefore, activation procedures are usually applied to develop their porous texture further, giving rise to activated carbons (ACs) with well-developed micromesoporosity and high surface area [9].

ACs with developed porosities have been widely used as electrodes in energy-storage devices such as supercapacitors (SCs), which store energy by separating and accumulating electrolyte ions on the electrode surfaces with opposite charge [16-19]. They typically store 10 to 100 times more energy per unit mass than electrolytic capacitors, tolerate many more charge - discharge cycles than rechargeable batteries, and can be fully charged and discharged in seconds, exhibiting high power densities. Nevertheless, these advantages are generally hampered by the presence of randomly connected micropores (size $<2 \mathrm{~nm}$ ) that are hardly accessible by electrolyte ions [20]. ACs with hierarchical porosities have been shown to be advantageous as electrode materials because micropores increase charge storage while mesopores (2 to $50 \mathrm{~nm}$ size) promote charge propagation at high current [21]. Capacitance, energy density and power density of carbon electrodes in SCs can be influenced by the volume and size of mesopores, so it is desirable to achieve a balanced population of micro and mesopores for efficient electrochemical storage.

In this study, we have successfully prepared for the first time carbon gels from phenolic oils by base-catalysed sol-gel polymerisation. This is a novel approach to the synthesis of carbon gels, which should take advantage of all the major components of phenolic oils as precursors rather than just their phenolic fraction. Organic gels were synthesised using formaldehyde as the 
crosslinker, $n$-propanol as a solvent and sodium hydroxide as a catalyst. They were dried under subcritical conditions and the resultant xerogels were submitted to carbonisation and chemical activation in a one-step process, using different $\mathrm{KOH}$ to organic gel mass ratios. The obtained ACs presented high mesopore volumes and were applied as electrode materials to store energy in supercapacitors, which is an important step towards upgrading such industrial coal-derived liquids. To evaluate the feasibility of industrial applications of the ACs thus obtained, their electrochemical performances were compared to those of a commercial and coal-derived AC.

\section{Experimental section}

\subsection{Materials}

Phenolic oil (PO) was obtained by purification of coal tar fractions and supplied by BASA Company (Spain). Sodium hydroxide (reagent grade, 97\%), $n$-propanol (ACS reagent, $\geq 99.9 \%$ ), potassium hydroxide pellets ( $\geq 84 \%$ ), formaldehyde (37\%, stabilised with methanol) and acetylene black powder $(<100 \mathrm{~nm})$ were purchased from Sigma-Aldrich. A solution of sulphuric acid (2 mol L-1) was prepared from a concentrated sulphuric acid solution (95-98\%) provided by Sigma-Aldrich. Hydrochloric acid $\left(1 \mathrm{~mol} \mathrm{~L}^{-1}\right)$ was purchased from VWR. Water (HPLC Gradient Grade) was purchased from Carl Roth. Polytetrafluoroethylene (PTFE) and glass fibre separator were provided by Aldrich and Pall Life Sciences, respectively. Commercial AC, MSP20X, was purchased from Kansai Coke and Chemicals Co., Ltd (Japan). All the materials were used as received.

\subsection{Xerogel synthesis}


A mixture containing phenolic oil (PO), formaldehyde (F), n-propanol (Pro) and sodium hydroxide (Na) in a proportion by weight of 31.7 \% PO / 31.7 \% F / 33.6 \% Pro / 3.0 \% Na (total mass $100 \mathrm{~g}$ ) was stirred at room temperature until complete dissolution of the sodium hydroxide. The final mixture was poured into a glass bottle $(250 \mathrm{~mL})$ closed with a cap supporting a maximum temperature of $140^{\circ} \mathrm{C}$, and heated in an oven $\left(85^{\circ} \mathrm{C}, 7\right.$ days). The solid product was recovered, dried in a ventilated oven $\left(60^{\circ} \mathrm{C}, 12 \mathrm{~h}\right)$ and ground in a ball mill (500 rpm, $\left.30 \mathrm{~min}\right)$.

\subsection{Synthesis of carbon materials}

A mixture containing different $\mathrm{KOH}$ / xerogel weight ratios ( $\mathrm{W}=2,3,4$ or 5) was placed in a nickel boat and heated at $5^{\circ} \mathrm{C} \mathrm{min}^{-1}$ under nitrogen flow $\left(100 \mathrm{~mL} \mathrm{~min}{ }^{-1}\right)$ until the selected activation temperature $\left(750^{\circ} \mathrm{C}\right)$. Once the target temperature was reached, the sample was held during the activation time $(1 \mathrm{~h})$ and then cooled down to room temperature under nitrogen flow (100 mL min $\left.{ }^{-1}\right)$. The resultant ACs were repeatedly washed with $1 \mathrm{~mol} \mathrm{~L}^{-1} \mathrm{HCl}$ solution and then with distilled water until they were free of chloride ions. Finally, they were dried at $105^{\circ} \mathrm{C}$ for 12 h, ground with a Retsch MM 400 vibrational ball mill (10 min) and labelled CXW, where CX refers to carbon xerogel and $\mathrm{W}$ to the $\mathrm{KOH} /$ organic xerogel mass ratio. The ACs were named CX2, CX3, CX4 and CX5, where $\mathrm{W}=2,3,4$ or 5. The carbon xerogel called CX0, where $\mathrm{W}=$ 0, was obtained by carbonisation of the organic precursor at $900^{\circ} \mathrm{C}$. The commercial AC, MSP20X, was also used for comparison purposes.

\subsection{Materials characterisation}

The chemical composition of the PO was determined by gas chromatography with a Perkin Elmer Autosystem chromatograph, using a $30 \mathrm{~m}$ long HP-5MS capillary column. Helium was used as carrier gas and the temperature of the injector was $320^{\circ} \mathrm{C}$. 
After materials synthesis, the carbonisation yield $(Y)$ of $\mathrm{CX} 0$ and the burn-off $(B O)$ of the ACs, CX2 to CX5, were calculated through Eq. 1 and 2, respectively:

$$
\begin{aligned}
& Y(\%)=\frac{m_{1}}{m_{0}} \times 100 \\
& B O(\%)=\frac{m_{0}-m_{1}}{m_{0}} \times 100
\end{aligned}
$$

where $m_{0}(\mathrm{~g})$ is the mass of organic gel and $m_{1}(\mathrm{~g})$ is the mass of AC.

The real density, $\rho_{R}\left(\mathrm{~g} \mathrm{~cm}^{-3}\right)$, defined as the mass of a unit volume of solid carbon skeleton, was measured with a Micromeritics AccuPyc 1340 pycnometer equipped with a $1 \mathrm{~cm}^{3}$ chamber, using helium as the displacement fluid. This measurement assumes that helium enters the smallest pores of the material without being adsorbed.

Nitrogen adsorption-desorption isotherms were obtained at $-196^{\circ} \mathrm{C}$ using a Micromeritics ASAP 2020 automatic system, while carbon dioxide adsorption isotherms were acquired at $0^{\circ} \mathrm{C}$ with a Micromeritics ASAP 2420 device. The pore size distributions (PSDs) of the carbon materials were obtained by applying the Non-Local Density Functional Theory (2D-NLDFT, SAIEUS software) to both the $\mathrm{N}_{2}$ and the $\mathrm{CO}_{2}$ isotherms. The surface areas were calculated by applying: (i) the BET equation to the nitrogen isotherms as detailed in [22], leading to $A_{B E T}\left(\mathrm{~m}^{2}\right.$ $\mathrm{g}^{-1}$ ); and (ii) the Non-Local Density Functional Theory (2D-NLDFT-HS), with SAIEUS software, to both $\mathrm{N}_{2}$ and $\mathrm{CO}_{2}$ isotherms, leading to $S_{N L D F T}\left(\mathrm{~m}^{2} \mathrm{~g}^{-1}\right)$ [23]. The surface areas of the micropores and mesopores, $S_{\text {micro }}$ and $S_{\text {meso }}\left(\mathrm{m}^{2} \mathrm{~g}^{-1}\right)$, respectively, were calculated from the PSDs [22]. The total pore volumes, $V_{T}$ and $V_{N L D F T}\left(\mathrm{~cm}^{3} \mathrm{~g}^{-1}\right)$, were determined from the $\mathrm{N}_{2}$ isotherms and from the PSDs, respectively [22]. The micropore volumes were calculated by applying: (i) the Dubinin-Radushkevich (DR) equation to the $\mathrm{N}_{2}$ adsorption isotherms, leading to $V_{\mu-N 2}\left(\mathrm{~cm}^{3} \mathrm{~g}^{-}\right.$ 
1) [24]; (ii) the Dubinin-Radushkevich (DR) equation to the $\mathrm{CO}_{2}$ isotherms, leading to $V_{\mu-\mathrm{CO}}$ $\left(\mathrm{cm}^{3} \mathrm{~g}^{-1}\right.$ ) [24]; (iii) the 2D-NLDFT-HS to both the $\mathrm{N}_{2}$ and $\mathrm{CO}_{2}$ isotherms, giving rise to $V_{\text {micro }}(w$ $<2 \mathrm{~nm}), V_{w<0.5}, V_{0.5<w<0.7}$ and $V_{0.7<w<2}\left(\mathrm{~cm}^{3} \mathrm{~g}^{-1}\right)[22]$. The mesopore volume, $V_{\text {meso }}\left(\mathrm{cm}^{3} \mathrm{~g}^{-1}\right)$, was calculated by subtracting $V_{\text {micro }}$ from $V_{N L D F T}$. The micropore and mesopore fractions, $\% V_{\text {micro }}$ and $\% V_{\text {meso }}$, were calculated as $\left(V_{\text {micro }} / V_{N L D F T}\right) \times 100$ and $\left(V_{\text {meso }} / V_{N L D F T}\right) \times 100$, respectively. The average micropore diameter, $w_{0}(d V)$, was calculated from the PSDs [22].

Elemental analysis was performed with an Elementar Vario EL Cube analyser as detailed in [25], and X-ray photoelectron spectroscopy (XPS) data were recorded with an ESCAPlus OMICROM system equipped with a hemispherical electron energy analyser as detailed in [26].

Scanning electron microscopy (SEM) images were obtained with a FEI XL30 SFEG electron microscope. EDX analyses were carried out with an Oxford Instrument EDS SDD XMAX detector $\left(80 \mathrm{~mm}^{2}\right)$ at $15 \mathrm{kV}$ on an average area of approximately $25 \times 25 \mu \mathrm{m}$. All samples were metallised with carbon to evacuate the electrostatic charges generated under the beam. The secondary electron images were taken with an acceleration voltage of 3 or $5 \mathrm{kV}$ to account for the extreme surface of each sample, and an acceleration tension of $10 \mathrm{kV}$ was applied to perform the chemical mapping of the materials by backscattered electrons analysis.

Raman spectroscopy was performed using an XploRa Raman spectrometer (Horiba) without sample preparation. The spectra were collected under a microscope using a $50 \times$ objective. The Raman-scattered light was dispersed by a holographic grating with 1200 lines/mm and detected by a CCD camera. The wavelength of the laser was $532 \mathrm{~nm}$, corresponding to the incident energy of $2.33 \mathrm{eV}$. The laser was filtered at $10 \%$ of its nominal power, thus corresponding to $1.8 \mathrm{~mW}$ applied to the sample. This value is a compromise between too high power resulting in some 
visible changes in the spectra over time, suggesting a heating and damage of the sample under the laser beam, and too low power for which the signal-to-noise ratio would have been poor. Each spectrum was obtained by accumulation of two spectra recorded from 800 to $3700 \mathrm{~cm}^{-1}$ over $180 \mathrm{~s}$. It was systematically checked that no significant difference was observed when the analysis was performed at different, visually comparable places of the same sample, suggesting the homogeneity of the materials.

X-ray diffraction (XRD) patterns of carbons were recorded with a Panalytical X'Pert Pro diffractometer. The latter was equipped with a $\mathrm{Cu}$ (Ko radiation) anticathode and a high-speed multichannel X'Celerator detector (scanning range of Bragg angle $2 \theta=15-70^{\circ}$; step size $=$ 0.0167), and was used in a Bragg-Brentano configuration in reflection mode.

FT-IR microscopy of the carbon electrodes was performed with a Perkin Elmer Frontier SPOTLIGHT 400 FT-IR microscope. Details on the electrode preparation are given below, in the part related to electrochemical characterisation. The FT-IR spectra of the powdered carbon material, the polytetrafluoroethylene (PTFE) binder, and the carbon black, were obtained by diffuse reflectance using a Perkin Elmer Frontier FT-IR spectrometer. In both cases, the measurements were carried out in the wavenumber range of 4000 to $650 \mathrm{~cm}^{-1}$, and each spectrum was obtained as an average of four accumulations with a resolution of $4 \mathrm{~cm}^{-1}$.

The contact angle of the carbon electrodes with the $2 \mathrm{M} \mathrm{H}_{2} \mathrm{SO}_{4}$ electrolyte was measured at room temperature with a Krüss - DSA 100 Drop Shape Analyser. The baseline was adjusted manually, and the contact angle was determined by the sessile drop method, analysing the shape of the electrolyte drop with the high-resolution camera of the instrument and applying the ADVANCE software [27]. 
The electrical conductivity of the carbon electrodes was measured by the four-probe method with a Keithley 6430 source - measure sub-femto-ammeter. The carbon electrodes had a diameter of $0.6 \mathrm{~cm}$ and their thickness $(\sim 0.3 \mathrm{~mm})$ was determined as the average value of ten measurements using a Keyence LK-G32 non-contact profilometer. Electric contacts were ensured by copper wires glued with silver paint to the ends of the samples. A current ranging from 0.1 to $10 \mathrm{~mA}$, depending on the resistivity of the samples, was imposed across their thickness, and the corresponding voltage drop was measured accordingly. It has always been checked that the current-voltage characteristics obey Ohm's law at room temperature, and all measurements have been corrected for the thermoelectric effect by reversing the current and calculating the average of the voltage drops with the current flowing in one direction and then in the other.

Electrochemical characterisation was performed with a Biologic VMP3 electrochemical workstation. The carbons were previously ground with a Retsch MM 400 vibrational ball mill (10 $\mathrm{min})$, and the carbon electrodes $\left(10 \mathrm{mg} \mathrm{cm}^{-2}, 0.5 \mathrm{~cm}\right.$ diameter) were prepared from a paste containing the carbon material, polytetrafluoroethylene (PTFE) binder and carbon black in the weight percent ratio of $85: 10: 5$. They were afterwards impregnated with the electrolyte (2M $\mathrm{H}_{2} \mathrm{SO}_{4}, 5$ days, under vacuum) and symmetrical supercapacitors were assembled by placing two identical electrodes separated by a glass fibre disc between two gold current collectors.

Galvanostatic charge-discharge (GCD) experiments were thus performed in a two-electrode cell at constant currents ranging from 0.1 to $12 \mathrm{~A} \mathrm{~g}^{-1}$, based on the total mass of the two electrodes. The most appropriate method for determining the capacitance of supercapacitors is based on the galvanostatic discharge curves, as it is better correlated to the operating conditions 
of practical devices [28]. The cell capacitance $\left(C_{2 e, G C D}, \mathrm{~F} \mathrm{~g}^{-1}\right)$ was therefore determined from the galvanostatic discharge curves using Eq. (3):

$$
C_{2 e, G C D}=I /[m(d V / d t)]
$$

where $I(\mathrm{~A})$ is the constant discharge current, $m(\mathrm{~g})$ is the mass of carbon in the two electrodes and $d V / d t\left(\mathrm{~V} \mathrm{~s}^{-1}\right)$ is the slope of the discharge curve without taking into account the voltage drop, IR (V), due to the inner resistance at the beginning of the discharge process. The gravimetric capacitance expressed for a single electrode $\left(C_{l e, G C D}, \mathrm{~F} \mathrm{~g}^{-1}\right)$ can be estimated through Eq. (4):

$$
C_{1 e, G C D}=4 \times C_{2 e, G C D}
$$

\section{where $C_{2 e, G C D}\left(\mathrm{~F} \mathrm{~g} \mathrm{~g}^{-1}\right)$ is the specific capacitance of the two-electrode system.}

Since the capacitance varies with voltage, it should be calculated within the typical voltage window in which the device will operate. Practical supercapacitors are normally operated between $V_{\max }$ and $1 / 2 V_{\max }$, so the capacitance should be calculated taking into account the slope of the discharge curve indicated in Eq. (5):

$$
\frac{d V}{d t}=\frac{V_{\text {max }}-1 / 2 V_{\text {max }}}{t_{2}-t_{1}}
$$

where $t_{2}$ and $t_{1}$ are the discharge times at $1 / 2 V_{\max }$ and $V_{\max }$, respectively. Including the lower half of the discharge curve in the calculation of the slope, i.e., from $1 / 2 V_{\max }$ to $0 \mathrm{~V}$, can distort the apparent capacitance above the value that is practically attainable for real devices. The introduction of significant errors in the calculation of the capacitance by the method used to calculate the slope of the discharge curve has already been demonstrated [28]. 
In the case of packaged cells, the cell resistance $R_{\text {cell }}$ is determined from the GCD tests in constant current mode and considering the $I R$ drop at the beginning of the discharge curve. As the current passed directly from the full charge to the full discharge, $R_{\text {cell }}$ was calculated by dividing the $I R$ drop by twice the applied current [29].

The energy density was determined from the cell capacitance and the electrochemical voltage window, and it is currently the limiting factor for practical supercapacitors. The energy $(E)$ and power $(P)$ densities were calculated according to Eq. (6) and (7), respectively:

$$
\begin{aligned}
& E=\frac{1}{2} C_{2 e, G C D} \Delta V_{d}^{2} \\
& P=E / \Delta t_{d}
\end{aligned}
$$

where $C_{2 e, G C D}\left(\mathrm{~F} \mathrm{~g} \mathrm{~g}^{-1}\right)$ is again the specific capacitance obtained from Eq. 3 which considers the mass of the two electrodes, $\Delta V_{d}(\mathrm{~V})$ is the operation voltage calculated as $V_{\max }-I R$, where $I R(\mathrm{~V})$ is again the voltage drop at the beginning of the discharge curve, and $\Delta t_{d}(\mathrm{~s})$ is the discharge time.

The cycling stability or cycling life was studied through GCD tests up to 10000 chargedischarge cycles. A high charge-discharge current of $5 \mathrm{~A} \mathrm{~g}^{-1}$ was selected to avoid large capacitance errors obtained when using low discharge rates, especially when coupled with low masses of electrodes [28].

Cyclic voltammetry (CV) tests were also used to study the electrochemical performances of the materials, especially their rate capability. It is important for commercial devices to achieve high rate capabilities as they must be efficient in high scan rate and high current density regimes. $\mathrm{CV}$ tests were thus performed in a two-electrode cell at scan rates between 1 and $1000 \mathrm{mV} \mathrm{s}^{-1}$ 
within the voltage range of $0-1 \mathrm{~V}$ and using $2 \mathrm{M} \mathrm{H}_{2} \mathrm{SO}_{4}$ as the electrolyte. The voltage range used to test the cells corresponds to the maximum potential window used for aqueous electrolytes. The specific capacitance of the two-electrode system $\left(C_{2 e, C V}, \mathrm{~F} \mathrm{~g}^{-1}\right)$ was calculated from the CV curves according to Eq. (8):

$$
C_{2 e, C V}=\left(\int I \Delta V\right) /(s d V m)
$$

where $I(\mathrm{~A})$ is the current, $s\left(\mathrm{~V} \mathrm{~s}^{-1}\right)$ is the scan rate, $\Delta V(\mathrm{~V})$ is the potential window and $m(\mathrm{~g})$ is the mass of carbon in the two electrodes. The gravimetric capacitance for a single electrode, $C_{l e, G C D}$, can be estimated through Eq. (4).

Finally, electrochemical impedance spectroscopy (EIS) measurements were also performed in a two-electrode cell at open-circuit voltage (OCV) within the frequency range $100 \mathrm{kHz}$ to 1 $\mathrm{mHz}$, with an alternating current amplitude of $10 \mathrm{mV}$. The frequency response of the materials was determined by the relaxation time constant, $\tau_{0.5}$, from the Bode plot. $\tau_{0.5}$ is calculated as $1 / f_{0.5}$, where $f_{0.5}$ is the frequency at which $50 \%$ of the normalised capacitance is obtained.

\section{Results and discussion}

\subsection{Physicochemical and structural properties}

The main PO components, determined by gas chromatography, were $14.80 \%$ phenol, $26.17 \%$ indane, $11.54 \%$ indene, $2.34 \%$ coumarone, $8.13 \%$ naphthalene, $11.02 \%$ o,m,p-cresol and 1.14\% o,m,p-xylenol. As a result, the carbonisation yield of CX0 was $30.19 \%$, i.e., significantly lower than that of most polyphenol-based gels, which is rather slightly less than $50 \%[30,31]$. This finding suggests that, as expected from the analysis, only a fraction of PO corresponds to the 
actual phenolic material available for gelation. It also indicates that, as expected, other components than phenol reacted and became part of the final carbon materials.

The burn-off $(B O)$ of the PO-derived ACs increased from $80.6 \%$ for CX2 to $94.1 \%$ for CX5. CX3 and CX4 presented similar $B O$ values of 81.2 and $81.9 \%$, respectively. Thus, from a practical point of view, $\mathrm{W}>4$ would not be appropriate because the amount of AC obtained is very low and the porosity of the material was not developed further, as shown below. The POderived carbons exhibited real densities lower than $2 \mathrm{~g} \mathrm{~cm}^{-3}$, as expected for phenolic precursors: that of CX0 was $1.58 \mathrm{~g} \mathrm{~cm}^{-3}$, while that of the ACs ranged from 1.86 to $2.00 \mathrm{~g} \mathrm{~cm}^{-3}$. The real density of MSP20X was $1.99 \mathrm{~g} \mathrm{~cm}^{-3}$.

Nitrogen isotherms and PSDs of the carbon materials are displayed in Fig. S1. The resultant textural parameters are shown in Fig. $\mathbf{1}$ and in Table S1 in the Supporting Information section. The nitrogen isotherm of CX0 exhibited a low uptake, indicating that the material had a poorly developed porous texture (Fig. S1a). The latter was typical of a carbon xerogel, mainly composed of mesopores (93.1\%) and a low percentage of micropores (6.9\%) narrower than 0.5 nm (Fig. 1, Fig. S1b and Table S1 in the Supporting Information) [11]. The micropores were hardly accessible to nitrogen, based on the facts that $S_{N L D F T}>A_{B E T}$ and $V_{\mu-C O 2}>V_{\mu-N 2}$ (Table S1). $S_{N L D F T}$ and $V_{N L D F T}$ of CX0 were $102 \mathrm{~m}^{2} \mathrm{~g}^{-1}$ and $0.14 \mathrm{~cm}^{3} \mathrm{~g}^{-1}$, respectively. As expected, activation with $\mathrm{KOH}$ significantly developed the porous texture of the raw material: the nitrogen isotherms of the ACs were type I, typical of microporous materials, and had considerably higher nitrogen uptakes than CX0. The latter increased due to the generation of micropores and of mesopores with size between 2 and 4 nm (Fig. 1b and Table S1 in Supporting Information). Considering that $A_{B E T}$ overestimates the porosity of highly microporous materials [32], $S_{N L D F T}$ should be used. According to Table S1 (Supporting Information), CX3 had the highest $S_{\text {micro }}$ of 
$1757 \mathrm{~m}^{2} \mathrm{~g}^{-1}, V_{\text {micro }}$ of $0.90 \mathrm{~cm}^{3} \mathrm{~g}^{-1}$, and $V_{0.7<w<2}$ of $0.80 \mathrm{~cm}^{3} \mathrm{~g}^{-1}$, and reached the highest $S_{N L D F T}$ and $V_{\text {micro }}$ of the series, $2041 \mathrm{~m}^{2} \mathrm{~g}^{-1}$ and $0.90 \mathrm{~cm}^{3} \mathrm{~g}^{-1}$, respectively. This suggests that CX3 possessed the most developed microporosity and, therefore, $\mathrm{W}=3$ should be considered as the optimum activation ratio. CX4 reached the highest $S_{\text {meso }}$ and $V_{\text {meso }}$ of the series of materials, 368 $\mathrm{m}^{2} \mathrm{~g}^{-1}$ and $0.45 \mathrm{~cm}^{3} \mathrm{~g}^{-1}$, respectively, while CX5 had lower micropore and mesopore volumes than CX4 due to the widening of the pore diameter and to the loss of microporosity (Fig. 1, Fig. S1b and Table S1 in the Supporting Information).

CX0 presented the lowest average micropore size, $w_{0}(d V)=0.42 \mathrm{~nm}$ (Fig. S1b and Table S1, Supporting Information). As $\mathrm{W}$ increased from 2 to 5, there was a progressive widening of the pore diameter, as evidenced by: i) the decrease in micropore fraction, $\% V_{\text {micro }}$, ii) the increase in mesopore fraction, $\% V_{\text {meso }}$, and iii) the increase in the average micropore size, $w_{0}(d V)$ (Fig. 1d and Table S1). 


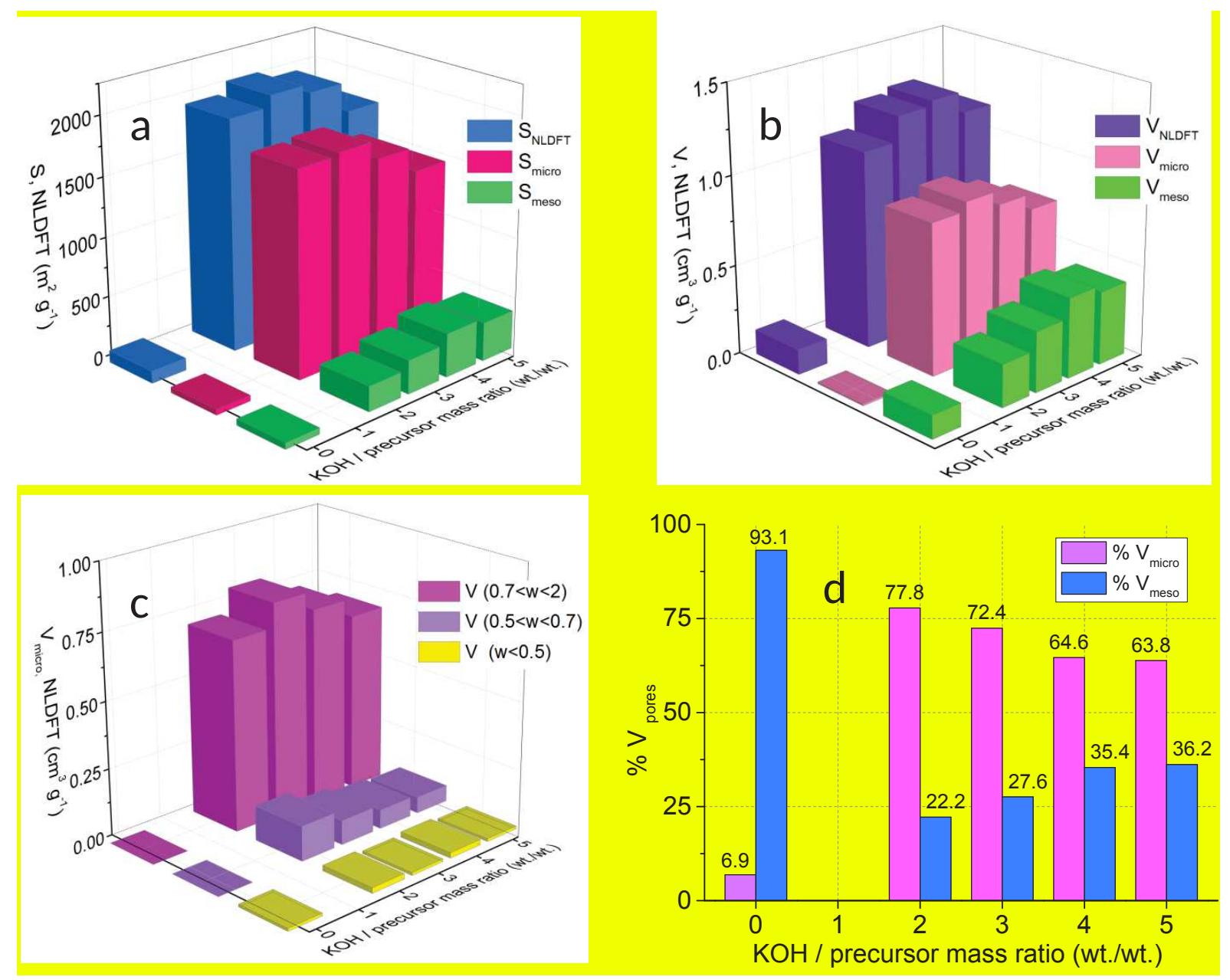

Figure 1. Representation of some textural parameters of the carbons, calculated from the PSDs, with respect to the $\mathrm{KOH} /$ precursor mass ratio (wt. / wt.): (a) $S_{N L D F T}, S_{\text {micro }}$ and $S_{\text {meso }}$; (b) $V_{N L D F T}$, $V_{\text {micro }}$ and $V_{\text {meso }}$; (c) $V_{0.7<w<2}, V_{0.5<w<0.7}$ and $V_{w<0.5}$; (d) $\% V_{\text {micro }}$ and $\% V_{\text {meso }}$.

The porous texture of MSP20X was mainly composed of micropores, which represent $93.4 \%$ of the total pore volume, and a small percentage of mesopores, 6.6\% (Table S1, Supporting Information). It exhibited higher $S_{\text {micro }}, 1955 \mathrm{~m}^{2} \mathrm{~g}^{-1}$, than that of the ACs exhibiting the most developed porosities, CX3 and CX4, but similar $S_{N L D F T}, 2007 \mathrm{~m}^{2} \mathrm{~g}^{-1}$, and its average micropore size was lower than that of PO-derived ACs, $w_{0}(d V)=1.04 \mathrm{~nm}$. Moreover, its mesopore fraction was much lower than that of the PO-derived AC having the least developed porosity, 22.2\% for 
CX2. Thus, the use of PO as precursor allowed obtaining ACs with similar surface areas but much higher mesopore volumes than commercial ACs. The effect of higher mesopore volumes of PO-derived ACs on their electrochemical performances compared to those of the commercial AC is discussed below.

The results of chemical analysis of the PO-derived ACs and of the commercial AC are shown in Fig. 2. CX0 possessed the highest bulk and surface O concentrations, 13.5 wt.\% and 10.7 at.\%, respectively (Fig. 2a and Table 1). It also contained other elements on its surface, such as $\mathrm{F}, \mathrm{K}$ and $\mathrm{Cl}$, which may be derived from the impurities of the reagents used to prepare it or be those already present in the PO, but no nitrogen was detected (Table 1). Chemical activation decreased the heteroatom content of the carbons with respect to CX0 due to the elimination of functional groups at the edge of the carbon layers, particularly oxygen groups. CX4 had the highest concentrations of total and superficial oxygen, 8.5 wt.\% and 5.7 at.\%, respectively, while CX3 had the lowest ones, 5.7 wt.\% and 4.7 at.\%, respectively (Fig. 2a and Table 1). CX0 was therefore the most functionalised material in its bulk, followed by CX4, as shown in the Van Krevelen diagram (Fig. 2b).

MSP20X presented a lower bulk oxygen concentration than the PO-derived ACs, 1.7 wt.\%, and the lowest $\mathrm{O} / \mathrm{C}$ ratio, indicating that it was the least bulk-functionalised material. The oxygen concentration determined by XPS, 4.7 at.\%, was considerably higher than that measured in its bulk by elemental analysis, 1.7 wt.\%, equivalent to 1.3 at.\% (Fig. 2 and Table 1). Unlike the POderived ACs, MSP20X presented a very low surface concentration of nitrogen, 0.1 at.\%. Fitting the N1s high-resolution spectrum of MSP20X was not possible because of the high noise of the curve. 

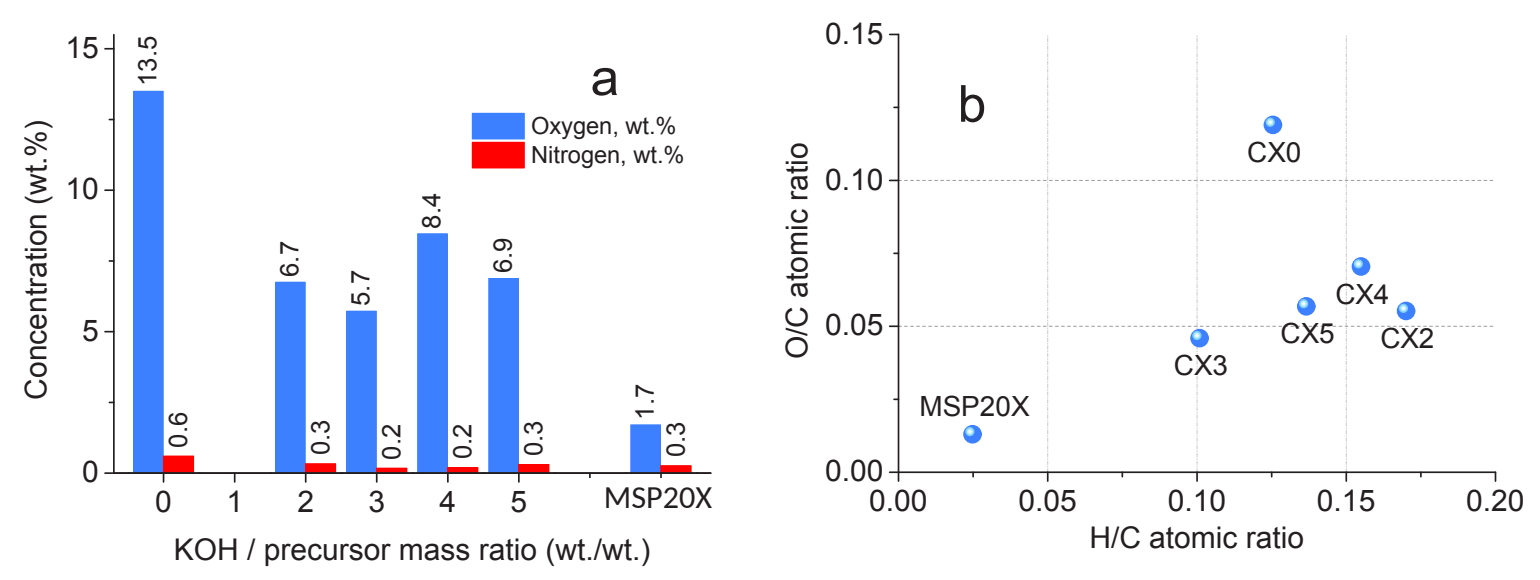

Figure 2. (a) Bulk oxygen and nitrogen concentration, and (b) Van Krevelen diagram of the studied materials.

The fitting of the C1s and O1s regions of the high-resolution spectra made it possible to identify different oxygen functionalities on the material surface (Fig. S2 and S3, Supporting Information). The most abundant oxygen groups were phenols, ethers, esters and anhydrides, followed by carbonyls, quinones and carboxylic acids (Table 1). Previous studies have shown that quinones and carbonyls are the most electrochemically active oxygen groups in protonic acidic electrolytes, such as sulphuric acid [33].

In general, the ACs surface chemistry changed with respect to that of the raw material as a result of chemical activation: i) chemically adsorbed water and oxygen, assigned to $\mathrm{O}^{*}$ and present on the surface of CX0, disappeared; ii) the relative concentrations of quinones, carbonyls and carboxylic acids, decreased; iii) the relative concentration of oxygen groups assigned to OII (hydroxyls, ethers, esters and anhydrides) increased; and iv) that assigned to OIII (esters, anhydrides and hydroxyls) decreased. Among the ACs studied, CX3 had the highest surface concentration of carbonyls, quinones and carboxylic acids (OI peak) but the lowest of the groups represented by OII (hydroxyls, ethers, esters and anhydrides). For CX4, the surface chemistry 
presented the opposite situation. However, since OII and OIII are assigned to C-O bonds that belong to different groups, and given the total amount of surface functionalities, it is not possible to determine whether the concentration of such oxygen functionalities has decreased or not.

SEM images revealed that CX0 was not only composed of uneven carbon particles, but also of fibres with well-defined edges (Fig. S4a-b - left row, Supporting Information). The average composition of the uneven carbon particles was 77.8 at.\% C, 18.7 at.\% O, 2.9 at.\% Na and 0.6 at.\% K, as determined by EDX (Fig. S4a - right row, Supporting Information). F and Cl, detected on the CX0 surface by XPS, were not identified by EDX, but the concentrations of C, $\mathrm{O}$, $\mathrm{Na}$ and $\mathrm{K}$ determined by both techniques were consistent. The composition of the fibres was very different from that of a carbon material, since it contained 29.2 at.\% C, 49.9 at.\% O and 20.9 at.\% Na (Fig. S4b - right row, Supporting Information). The chemical map obtained by SEM-EDX evidenced that elements such as C, Si, S and K were homogeneously distributed on the CX0 surface, while O and Na were more concentrated in certain areas (Fig. S5, Supporting Information). The fibres contained primarily $\mathrm{C}, \mathrm{O}$ and $\mathrm{Na}$ that were homogeneously distributed. 
Table 1. Contributions to the C1s and O1s high-resolution spectra obtained by XPS.*

\begin{tabular}{|c|c|c|c|c|c|c|c|c|c|c|c|c|}
\hline \multirow[t]{2}{*}{ Sample } & \multicolumn{3}{|c|}{$\begin{array}{l}\text { Conc. } \\
\text { (at.\%) }\end{array}$} & \multicolumn{5}{|c|}{$\begin{array}{l}\text { C1s } \\
\text { BE (eV) } \\
\text { A (\%) }\end{array}$} & \multicolumn{4}{|c|}{$\begin{array}{l}\text { O1s } \\
\text { BE (eV) } \\
\text { A (\%) }\end{array}$} \\
\hline & $\mathrm{C}$ & $\mathrm{O}$ & $\mathrm{N}$ & CI & CII & CIII & CIV & $\mathrm{CV}$ & OI & OII & OIII & O* \\
\hline $\mathrm{CX}^{* * *}$ & 85.0 & 10.7 & - & $\begin{array}{l}284.5 \\
63.7\end{array}$ & $\begin{array}{l}285.5 \\
28.1\end{array}$ & $\begin{array}{l}287.6 \\
3.9\end{array}$ & $\begin{array}{l}289.2 \\
1.8\end{array}$ & $\begin{array}{l}290.2 \\
2.4\end{array}$ & $\begin{array}{l}531.6 \\
32.0\end{array}$ & $\begin{array}{l}532.6 \\
41.0\end{array}$ & $\begin{array}{l}534.5 \\
11.1\end{array}$ & $\begin{array}{l}536.5 \\
15.9\end{array}$ \\
\hline CX2 & 95.2 & 4.8 & - & $\begin{array}{l}284.4 \\
62.6\end{array}$ & $\begin{array}{l}285.5 \\
27.8\end{array}$ & $\begin{array}{l}287.6 \\
5.3\end{array}$ & $\begin{array}{l}289.2 \\
2.7\end{array}$ & $\begin{array}{l}290.4 \\
1.5\end{array}$ & $\begin{array}{l}531.1 \\
29.4\end{array}$ & $\begin{array}{l}532.8 \\
69.7\end{array}$ & $\begin{array}{l}535.1 \\
0.9\end{array}$ & - \\
\hline CX3 & 95.3 & 4.7 & - & $\begin{array}{l}284.4 \\
57.6\end{array}$ & $\begin{array}{l}285.5 \\
30.3\end{array}$ & $\begin{array}{l}287.6 \\
7.3\end{array}$ & $\begin{array}{l}289.2 \\
2.5\end{array}$ & $\begin{array}{l}290.4 \\
2.3\end{array}$ & $\begin{array}{l}531.1 \\
32.6\end{array}$ & $\begin{array}{l}532.8 \\
63.9\end{array}$ & $\begin{array}{l}534.5 \\
3.5\end{array}$ & - \\
\hline CX4 & 94.3 & 5.7 & - & $\begin{array}{l}284.4 \\
65.4\end{array}$ & $\begin{array}{l}285.5 \\
24.8\end{array}$ & $\begin{array}{l}287.6 \\
7.0\end{array}$ & $\begin{array}{l}289.1 \\
1.6\end{array}$ & $\begin{array}{l}290.2 \\
1.2\end{array}$ & $\begin{array}{l}531.3 \\
16.5\end{array}$ & $\begin{array}{l}532.8 \\
82.7\end{array}$ & $\begin{array}{l}534.5 \\
0.7\end{array}$ & - \\
\hline CX5 & 95.2 & 4.8 & - & $\begin{array}{l}284.4 \\
61.7\end{array}$ & $\begin{array}{l}285.5 \\
26.2\end{array}$ & $\begin{array}{l}287.6 \\
7.9\end{array}$ & $\begin{array}{l}289.2 \\
2.0\end{array}$ & $\begin{array}{l}290.3 \\
2.1\end{array}$ & $\begin{array}{l}531.3 \\
26.5\end{array}$ & $\begin{array}{l}532.8 \\
67.3\end{array}$ & $\begin{array}{l}535.1 \\
6.2\end{array}$ & - \\
\hline MSP20X & 95.2 & 4.7 & 0.12 & $\begin{array}{l}284.5 \\
60.9\end{array}$ & $\begin{array}{l}285.5 \\
24.9\end{array}$ & $\begin{array}{l}287.6 \\
7.5\end{array}$ & $\begin{array}{l}289.2 \\
3.5\end{array}$ & $\begin{array}{l}290.7 \\
3.1\end{array}$ & $\begin{array}{l}531.4 \\
22.7\end{array}$ & $\begin{array}{l}532.9 \\
73.2\end{array}$ & $\begin{array}{l}534.5 \\
4.1\end{array}$ & - \\
\hline
\end{tabular}

*CI: hydrocarbons, aromatics and aliphatics; CII: $\mathrm{Csp}^{3}$ and C-O single bonds associated with ethers, phenols and anhydrides; CIII: $\mathrm{C}=\mathrm{O}$ double bonds in carbonyls and quinones; $\mathrm{CIV}$ : C-O single bonds in carboxyls; CV: plasmon losses or shake-up $\pi$ - $\pi$ satellites. OI: $\mathrm{C}=\mathrm{O}$ double bonds in quinone-type groups, carbonyls and carboxylic acids; $\mathrm{OII}$ : $-\mathrm{OH}$ bonds in phenols, $\mathrm{C}-\mathrm{O}-\mathrm{C}$ ether groups and $\mathrm{C}=\mathrm{O}$ bonds in ester and anhydride groups; OIII: single $\mathrm{C}-\mathrm{O}$ bonds in esters and anhydrides, $\mathrm{C}-\mathrm{O}$ bonds in carboxylic groups; $\mathrm{O}^{*}$ : chemisorbed oxygen and/or water [34]. BE (eV) and A (\%) stand for binding energy and relative contribution based on peak area, respectively.**Other elements were detected on the surface of CX0: 1.3 wt.\% Na, 0.4 wt.\% F, 0.5 wt.\% K and 2.0 wt.\% Cl. 
There was also a difference between the Raman spectra taken on points with and without these fibres. The spectra were recorded with the microscope objective of $50 \times$, which allowed analysing a surface of $10 \mu \mathrm{m}$ in diameter, so that it was not possible to investigate the fibrous particles alone without considering the Raman scattering of the carbon background. The spectrum of a fibre-free region showed two broad D and G bands located at 1360 and $1595 \mathrm{~cm}^{-1}$, respectively, typical of disordered carbon materials (Fig. 3). The intensity ratio, $I_{D} / I_{G}$, measured directly on the envelope of the spectrum and after baseline correction was 1.07. As we deal here with a non-graphitisable carbon, this value is expected to be proportional to the squared crystallite size, $L_{a}^{2}[35,36]$. The first-order parts of the Raman spectra of the PO-derived ACs were also typical of disordered carbon materials, with no peaks other than the broad D and G bands already seen in Fig. 3 (not shown). Therefore, the aromatic nature of the compounds contained in the PO used as precursor did not increase the nanotextural order of CX0 compared to that of other carbons obtained from biomass treated at similar temperature, for example in [37]. The Raman spectrum of a CX0 region containing fibres was similar to the previous one but exhibited an intense and very narrow peak at $1062 \mathrm{~cm}^{-1}$. The intensity ratio, $\mathrm{I}_{\mathrm{D}} / \mathrm{I}_{\mathrm{G}}$, calculated in the same way as above was 1.05 , indicating that the nanotextural order of the material was slightly lower in the presence of these fibres. Given this fact, the position and the width of the aforementioned peak and the chemical composition of the fibres determined by EDX, it is unlikely that these fibre-type particles are carbon, but an inorganic material.

Indeed, the XRD pattern revealed that the main crystalline phase present in CX0 was tronite, which is a sodium salt of formula $\mathrm{Na}_{3} \mathrm{H}\left(\mathrm{CO}_{3}\right)_{2} \cdot 2 \mathrm{H}_{2} \mathrm{O}$ produced by evaporation (Fig. S6, Supporting Information). The generation of such a sodium salt is consistent with the use of $\mathrm{NaOH}$ as catalyst to obtain the PO-derived gel and its subsequent carbonisation. Indeed, the 
weight fraction of $\mathrm{NaOH}$ in the synthesis of the organic gels was $3 \%$, and the concentration of sodium in the final material increased upon carbonisation. Given that the carbon yield of the organic gel was about $30 \%$, it means that the final concentration of $\mathrm{NaOH}$ in the carbon xerogel was $10 \%$, assuming no other reaction. Such amount is high enough to allow observing the tronite fibres in $\mathrm{CX}$. Moreover, $\mathrm{NaOH}$ added as a catalyst and present in the crude xerogel could also act as a co-activating agent along with $\mathrm{KOH}$ upon heat-treatment of the carbons [38]. Since the resultant ACs were thoroughly washed subsequently, no fibre-like particles or elements other than carbon or oxygen were found on their surfaces.

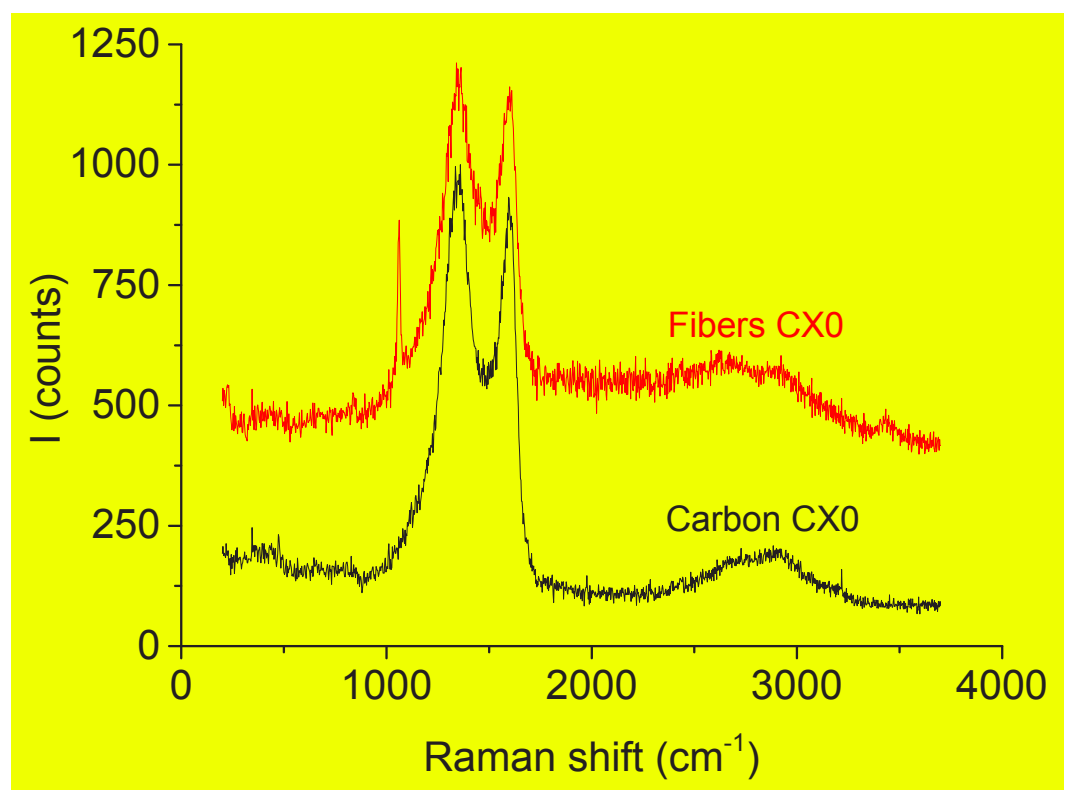

Figure 3. Raman spectra obtained on fibre-like particles and on uneven carbon particles of CX0. The intensity of the spectra was normalised and shifted for easier viewing.

The carbon distribution within the electrodes and the affinity of the latter for the electrolyte were studied by FTIR microscopy and contact angle measurements, respectively. By using FTIR microscopy, the chemical map of a representative electrode, CX4, was obtained for an 
electrode area of $100 \times 100 \mu \mathrm{m}$. The chemical map revealed the presence of three components identified as AC, PTFE and carbon black, which were found in the relative amounts of 85, 10.5 and 4.5\%, respectively (Fig. 4a and Fig. S7 in the Supporting Information). These data are in good agreement with the percentages by weight of each component added to make the electrode, which were about 85, 10 and 5 wt.\%, respectively, as indicated in the experimental section. Moreover, the chemical map displayed three main areas with slightly different transmittances, which appear in blue, green and pink colours (Fig. 4a). The FTIR spectra of the blue, green and pink colour domains presented bands at 1202 and $1146 \mathrm{~cm}^{-1}$, more or less intense depending on the region, which are assigned to PTFE. The bands appearing between $\sim 1000$ and $900 \mathrm{~cm}^{-1}$ are assigned to carbon black (Fig. 4a and Fig. S7 in the Supporting Information). 


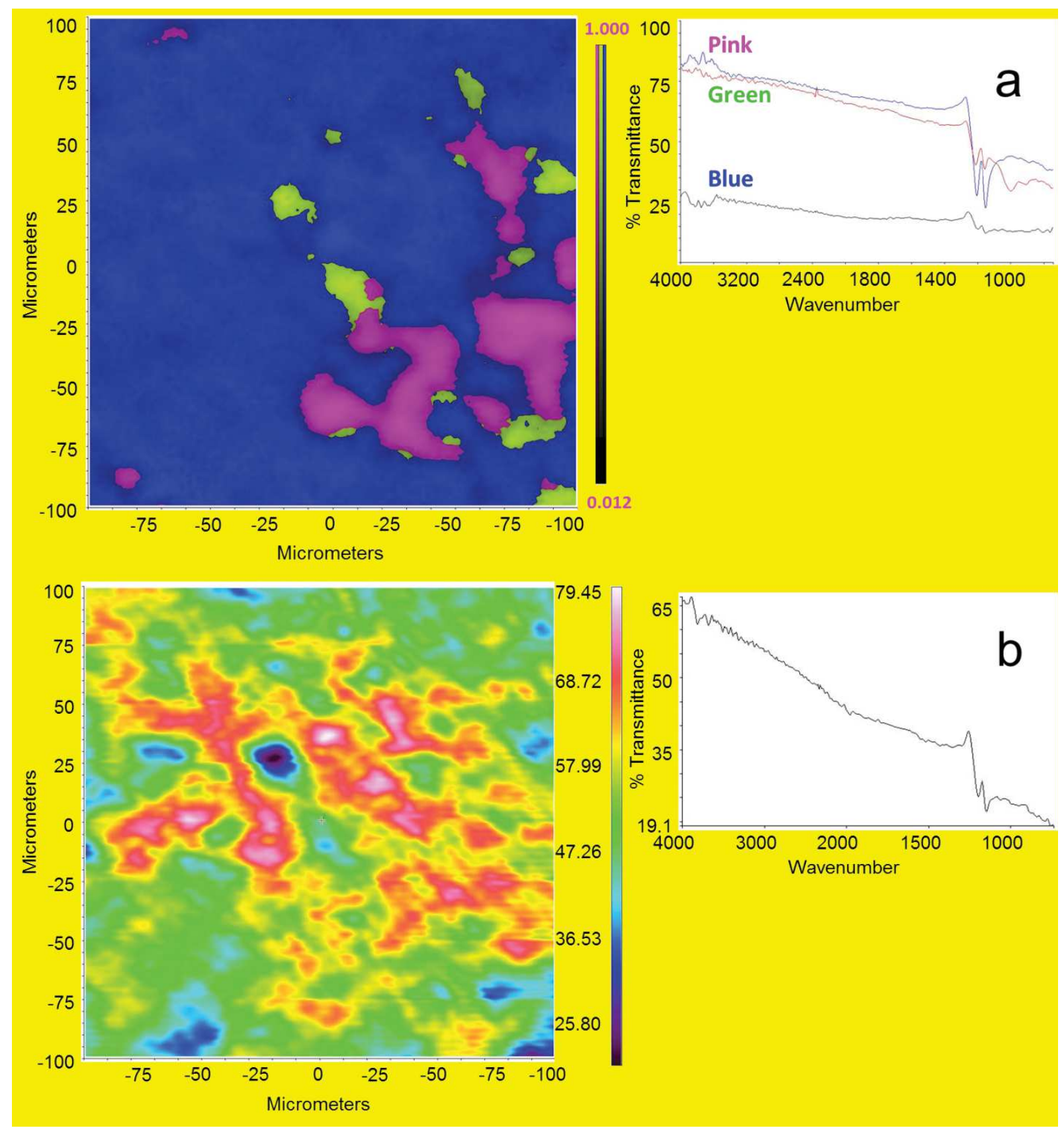

Figure 4. Characterisation of the CX4 electrode by FT-IR microscopy: (a) Chemical map (left) and FT-IR spectra of the regions exhibiting different absorption (right); (b) Average transmission picture (left) and average FT-IR spectrum (right). 
The average spectrum of the electrode, also taken in a $100 \times 100 \mu \mathrm{m}$ area, was the weighted average of the individual spectra of the three electrode components (Fig. 4b). Therefore, even though PTFE or carbon black may be somewhat more exposed in micrometric zones at the electrode surface, the three components were evenly distributed.

The contact angle between the electrodes and $2 \mathrm{~mol} \mathrm{~L}^{-1} \mathrm{H}_{2} \mathrm{SO}_{4}$ used as the electrolyte was higher than $90^{\circ}$ in all cases (Fig. S8, Supporting Information), thus indicating that the interaction between the electrode surface and the electrolyte was hydrophobic. The hydrophobic character of PTFE binder, which represents $10 \%$ of the electrode weight, is well known. Both the AC and the carbon black presented hydrophilic surfaces due to presence of oxygen surface groups. As the interaction between the electrode and the aqueous electrolyte was hydrophobic, this supports the fact that carbon, PTFE and carbon black were homogeneously distributed on the electrode surface. The contact angle of the MSP20X electrode was slightly higher than that of the POderived ones, which could correspond to a lower oxygen surface concentration. Therefore, the electrodes were held for 5 days with the electrolyte under vacuum to ensure that the electrolyte entered the micropore network of the carbons.

\subsection{Electrochemical properties}

Galvanostatic charge-discharge (GCD) experiments evidenced that the PO-derived ACs yielded higher capacitance values than the commercial MSP20X (Fig. 5a). CX2 had the highest capacitance $C_{2 e, G C D}=53 \mathrm{~F} \mathrm{~g}^{-1}\left(C_{l e, G C D}=212 \mathrm{~F} \mathrm{~g}^{-1}\right)$ at the lowest current of $0.2 \mathrm{~A} \mathrm{~g}^{-1}$, but it gradually decreased to $30 \mathrm{~F} \mathrm{~g}^{-1}$ as the current increased to $12 \mathrm{~A} \mathrm{~g}^{-1}$. The $C_{2 e, G C D}$ of CX5 was the same as that of CX2 at $12 \mathrm{~A} \mathrm{~g}^{-1}$, although it has a different porous texture. This may indicate that their fraction of microporosity accessible to the electrolyte ions and their surface chemistry are 
similar. Indeed, both samples had the same surface oxygen content, 4.8 at.\%, determined by XPS. Therefore, even though CX2 presented a more developed texture than CX5, a part of the narrow porosity was probably not accessible to the electrolyte and did not contribute to the capacitance. Moreover, since the mesopore volume and the mesopore fraction of CX2 are the lowest among the PO-derived ACs, the transport of ions is less facilitated from mesopores to micropores, and the kinetic limitations are higher than for the other PO-derived ACs (Table S1, Supporting Information) [21]. 

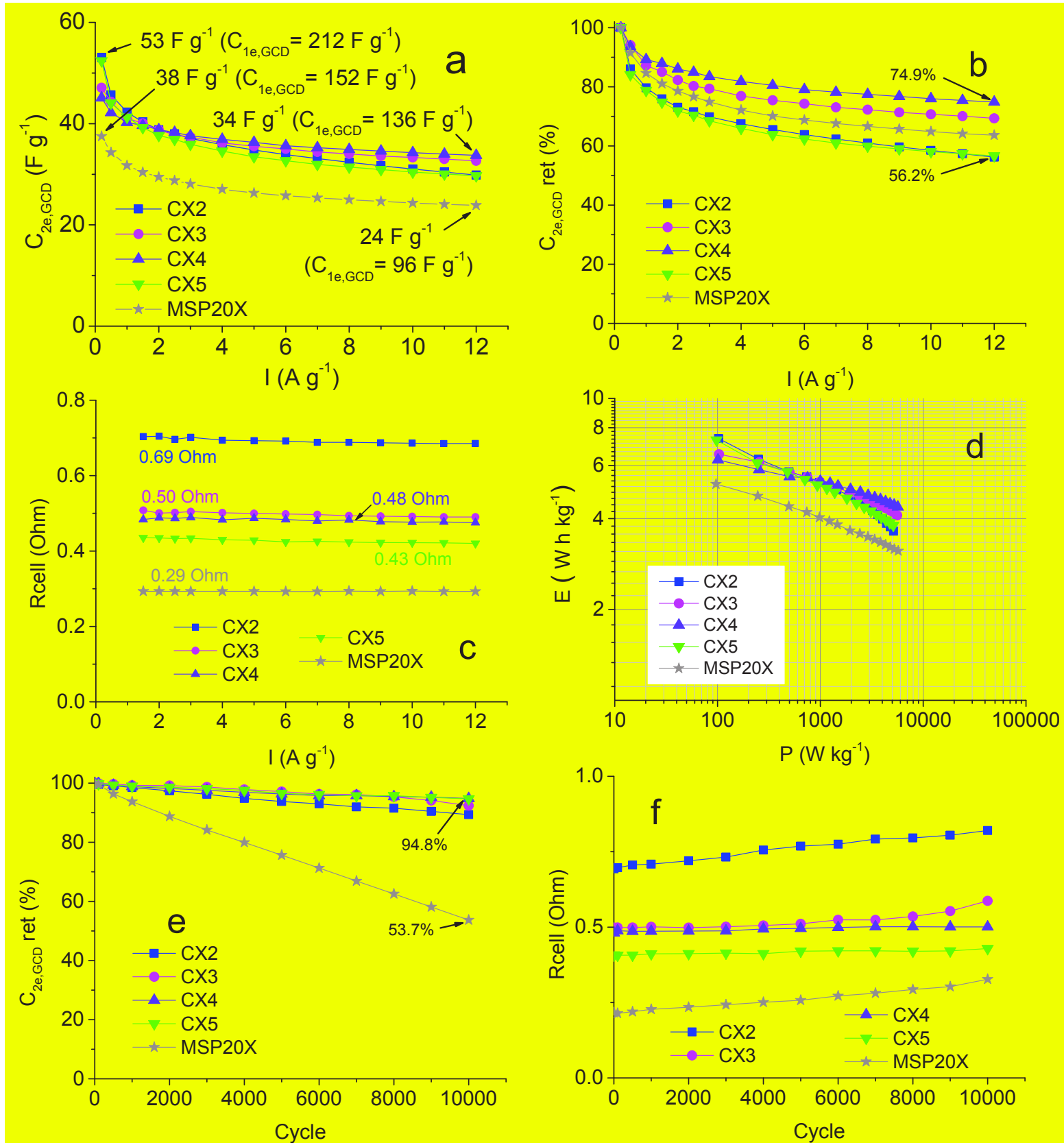

Figure 5. GCD data of the materials obtained in a 2-electrode cell between current densities of 0.2 and $12 \mathrm{~A} \mathrm{~g} \mathrm{~g}^{-1}$, considering the mass of the 2 electrodes: a) Gravimetric capacitance vs intensity; b) Capacitance retention vs intensity; c) Cell resistance vs intensity; d) Ragone plot; e) Cycling stability of the samples determined at $5 \mathrm{~A} \mathrm{~g}^{-1}$ up to 10000 charge-discharge cycles; $\mathrm{f}$ ) Evolution of cell resistance throughout 10000 charge-discharge cycles. 
CX4 led to the highest capacitance, $C_{2 e, G C D}=34 \mathrm{~F} \mathrm{~g}^{-1}\left(C_{l e, G C D}=136 \mathrm{~F} \mathrm{~g}^{-1}\right)$, and also to the highest capacitance retention of $74.9 \%$ at $12 \mathrm{~A} \mathrm{~g} \mathrm{~g}^{-1}$, mainly due to its high micropore and mesopore volumes, 0.82 and $0.45 \mathrm{~cm}^{3} \mathrm{~g}^{-1}$, respectively. CX4 not only exhibited the highest mesopore volume of the studied materials, but also the highest surface oxygen content, 5.7 at.\%, which may contribute to its high performances. The capacitance values of MSP20X were less affected by the current increase than those of CX2 and CX 5 were and, therefore, the capacitance retention of the former was higher, about $64 \%$ compared to about $56 \%$ for CX2 and CX5. MSP20X had the highest volume of narrow pores with size $<0.7 \mathrm{~nm}, 0.19 \mathrm{~cm}^{3} \mathrm{~g}^{-1}$, the lowest volume of mesopores, $0.06 \mathrm{~cm}^{3} \mathrm{~g}^{-1}$, and its surface oxygen content was similar to that of CX2 and CX5. Therefore, its capacitance retention cannot be explained by porous texture or surface chemistry. The electrical conductivity of the carbon electrodes is involved in the charge transfer between the electrode and the current collector. The higher the electrical conductivity, the higher the charge transfer, especially as the applied current increases [39]. As shown in Fig. S9 (Supporting Information), the MSP20X electrode had a conductivity about 10 times higher, in good agreement with its lower heteroatom content in the carbon bulk, than that of the PO-derived ACs, which compensates for the kinetic limitations of ion transport produced by the narrow porosity of the material, and contributes maintaining a high charge transfer at high current, thereby improving the capacitance retention. Other factors may explain these results, such as differences in pore tortuosity, since both types of ACs were prepared from completely different precursors and procedures.

The cell resistance, $R_{\text {cell }}$, depends on the resistance of the electrolyte, the intrinsic resistance of the active material, and the interfacial contact resistance between the active material and the current collector [40]. $R_{\text {cell }}$ was calculated from the GCD curves of the carbon electrodes as 
indicated in the Experimental section (Fig. S10 in Supporting Information). Due to its high electrical conductivity, MSP20X presented a lower inner cell resistance, $0.29 \Omega$, than the POderived ACs (Fig. 5c). Since the electrolyte was the same for all materials and the PO-derived ACs had similar electrical conductivities, $R_{\text {cell }}$ depended on the intrinsic resistance of the electrodes. Thus, the higher the mesopore fraction of the material, the lower the ion transport in the electrode and the lower the $R_{\text {cell }}$ CX2 had the highest $R_{\text {cell }}$ of $0.69 \Omega$ and CX5 had the lowest, $0.43 \Omega$

The PO-derived ACs produced higher energy and power densities (see Eq. (6) and (7), respectively) than MSP20X within the entire current interval (Fig. 5d). The energy density of MSP20X varied from 5.20 to $3.13 \mathrm{~W} \mathrm{~h} \mathrm{~kg}^{-1}$ at current densities ranging from 0.2 to $12 \mathrm{~A} \mathrm{~g}^{-1}$, respectively, and reached a maximum power density of $5.71 \mathrm{~kW} \mathrm{~kg}^{-1}$. On the one hand, CX2 and CX5 exhibited the highest energy densities of 7.37 and $7.28 \mathrm{~W} \mathrm{~h} \mathrm{~kg}^{-1}$, respectively, at the lowest current density of $0.2 \mathrm{~A} \mathrm{~g}^{-1}$. On the other hand, $\mathrm{CX} 4$ yielded the highest energy and power densities, $4.37 \mathrm{~W} \mathrm{~h} \mathrm{~kg}^{-1}$ and $5.70 \mathrm{~kW} \mathrm{~kg}^{-1}$, respectively, at the highest current density of $12 \mathrm{~A} \mathrm{~g} \mathrm{~g}^{-1}$, mainly thanks to its high micropore and mesopore volumes, as well as to its high surface oxygen content.

It therefore appears that the best performance is the result of a subtle balance between several effects: intrinsic properties of the materials on the one hand, but also conditions of use on the other hand. Thus, the NLDFT surface areas of CX2, CX3, CX4 and CX5 are 1946, 2041, 1968 and $1717 \mathrm{~m}^{2} / \mathrm{g}$, respectively, and are roughly proportional to the corresponding micropore volumes. Differences in surface area between CX2, CX3 and CX4 are less than 5\%, which is within the intrinsic error of gas adsorption analyses used for pore texture characterisation. 
At low current density, around $2 \mathrm{~A} / \mathrm{g}$, the capacitances are very similar for all the materials (see again Figure 5a) because of their very similar surface areas. It is well known that mesopores are necessary to improve ions diffusion, but there is still a significant fraction of mesoporosity, more than $20 \%$ in all the materials. Therefore, mesopores do not control the capacitances reached at $2 \mathrm{~A} / \mathrm{g}$.

However, at $12 \mathrm{~A} / \mathrm{g}$, the order in the capacitance values and capacitance retentions of the materials (Figure $5 \mathrm{~b}$ ) is $\mathrm{CX} 4>\mathrm{CX} 3>\mathrm{CX} 2=\mathrm{CX} 5$. The mesopore volume has a higher impact at high current density and therefore explains the capacitance retention in the order: $\mathrm{CX} 4>\mathrm{CX} 3>$ CX2, corresponding to mesopore volumes of $0.45>0.34>0.24 \mathrm{~cm}^{3} / \mathrm{g}$, respectively. CX5 has similar performances to $\mathrm{CX} 2$ although the latter has a higher mesopore volume $(0.41>0.24$ $\left.\mathrm{cm}^{3} / \mathrm{g}\right)$, but this fact is counterbalanced by a lower NLDFT surface area $\left(1717<1946 \mathrm{~m}^{2} / \mathrm{g}\right)$.

Given these results, CX4 should be a more suitable material for actual devices, which are expected to operate under high current density regimes. Moreover, the electrochemical performances of the PO-derived materials were higher than those of other previously published ACs in $\mathrm{H}_{2} \mathrm{SO}_{4}$ electrolyte [41], including those obtained from phenol-formaldehyde resins [42], pitch-derived ACs [43] or ACs obtained from resorcinol-formaldehyde xerogels [44], aerogels [45] and cryogels [46]. Other previously prepared carbon gels also present comparatively lower electrochemical performances in $\mathrm{KOH}$ electrolyte, such as $\mathrm{KOH}$-activated carbon aerogels [47], metal-doped carbon aerogels [48] or flexible and highly-graphitised carbon aerogels [49]. However, our values are lower than those obtained in $\mathrm{H}_{2} \mathrm{SO}_{4}$ electrolyte for nitrogen-doped carbon aerogels prepared from PEA/PVA- $\mathrm{H}_{3} \mathrm{BO}_{3}$ hydrogels and subsequently activated with $\mathrm{KOH}[\mathbf{5 0}]$. It is important to note that these previously studied materials were obtained from much more expensive, pure and single reagents, or from high-value coal tar fractions, while the 
PO-derived ACs studied in the present work were obtained from low-value coal tar liquids that do not have high-end applications so far. Consequently, the objective of valorising phenolic oils has been successfully attained through the preparation of promising electrode materials.

The PO-derived ACs had considerably higher cycling stabilities than MSP20X, ranging from 89.4 to $94.8 \%$ for CX2 and CX4, respectively, and 53.7\% for MSP20X. The loss of capacitance is due to the progressive degradation of the electrode with the increase of charge-discharge cycles, either because of the reduced access of the electrolyte to the narrow pores, or the progressive oxidation of the material by the formation of functional groups that increase $R_{\text {cell }}$, which are not electroactive or which give rise to irreversible reactions. The degradation of the electrode results in an increase of $R_{\text {cell }}$ throughout the 10000 charge - discharge cycles: $R_{\text {cell }}$ increased by $51.0 \%$ for MSP20X and between 4.1 and $18.3 \%$ for CX4 and CX2, respectively (Fig. 5f). This indicates that the MSP20X electrode was significantly more degraded that those made of PO-derived ACs. Moreover, as mesopores promote the transport of ions through the micropores, the higher the mesopore volume, the lower the increase of $R_{\text {cell }}$ and, consequently, the higher the capacitance retention after 10000 charge-discharge cycles (Table S1 and Fig. 5). In general, the PO-derived ACs exhibited higher cycling life than a broad variety of previously published materials $[\mathbf{6 , 5 1 , 5 2 ]}$. In this sense, the high micropore and mesopore volumes of CX4 appear to be optimal for obtaining high values of capacitance, energy and power densities under high current densities, as well as high cycling stabilities. Such electrochemical performances make this material a good candidate for actual devices.

The interfacial capacitance was calculated by dividing $C_{2 e, G C D}$ by the surface areas obtained by BET and NLDFT methods, i.e., $C_{2 e, G C D} / A_{B E T}$ and $C_{2 e, G C D} / S_{N L D F T}$, respectively (Fig. S11a-b, Supporting Information). CX5 exhibited the highest interfacial capacitance at low current and the 
differences among the studied ACs decreased as the current increased. Interfacial capacitance values at high current were slightly higher for the carbons having higher mesopore volumes, in the following order: CX5 > CX4 > CX3 > CX2 > MSP20X. Since interfacial capacitances are related to the pseudocapacitance contribution of the materials through Faradaic reactions, and given that CX5 exhibited similar oxygen content to that of CX2, CX3 and MSP20X, it means that mesopores facilitate the access of the aqueous electrolyte to the electroactive surface groups. In general, the specific capacitance $C_{2 e, G C D}$ was linearly proportional to the surface oxygen content of the materials, indicating that the oxygen groups on the material surface contributed to the total capacitance through Faradaic reactions (Fig. S11c). The specific capacitance of CX4 did not depend much on the oxygen surface content, thus confirming that the porous texture contributed mainly to the capacitance through well-balanced volumes of micropores and mesopores.

Due to the rapid development of wearable and miniaturised electronic devices in recent years, the volumetric performance of supercapacitors has attracted increasing interest. The volumetric capacitance was determined by dividing the specific capacitance by the volume of the two electrodes of the cell, $C_{2 e, G C D} / V_{\text {elec }}$ (Fig. S11d). Porous electrodes normally exhibit low packing densities, typically less than $0.75 \mathrm{~g} \mathrm{~cm}^{-3}$, and therefore, their volumetric capacitances are generally less than $200 \mathrm{~F} \mathrm{~cm}^{-3}$ [53]. Interestingly, CX5 had the highest volumetric capacitance of the PO-derived ACs at $0.2 \mathrm{~A} \mathrm{~g}^{-1}, 15.64 \mathrm{~F} \mathrm{~cm}^{-3}$, similar to that of the commercial AC, MSP20X, $15.11 \mathrm{~F} \mathrm{~cm}^{-3}$. CX3 and MSP20X presented the highest volumetric capacitances at the high current of $12 \mathrm{~A} \mathrm{~g}^{-1}$ among the studied carbons, i.e., $9.55 \pm 0.07 \mathrm{~F} \mathrm{~cm}^{-3}$, due to their comparatively lower electrode volumes. The CX4 electrode gave a volumetric capacitance of 8.98 $\mathrm{F} \mathrm{cm}^{-3}$ and $\mathrm{CX} 2$ and $\mathrm{CX} 5$ exhibited similar values of $8.79 \pm 0.07 \mathrm{~F} \mathrm{~cm}^{-3}$. The volumetric 
performances of the commercial AC and the PO-derived ACs are still low for application to miniaturised devices and should be improved, mainly by optimising the structural design of the device [53].

The curves obtained by cyclic voltammetry $(\mathrm{CV})$ testing of the studied materials exhibited rectangular shapes as the scan rate increased from 5 to $1000 \mathrm{mV} \mathrm{s}^{-1}$, indicating fast ion transport and fast charge propagation, and, therefore, high rate capability (Fig. 6a-b) [54,55]. The profile of the $\mathrm{CV}$ curves became gradually less deviated from the rectangular shape as the mesopore fraction in the PO-derived carbons increased (Fig. 6b). Since their electrical conductivities were similar, this clearly indicates that mesopores played a key role in their rate capabilities by facilitating the transport of ions. The CV curves of CX2, which had the lowest mesopore volume, $0.24 \mathrm{~cm}^{3} \mathrm{~g}^{-1}$, and the highest volume of narrow pores, $0.15 \mathrm{~cm}^{3} \mathrm{~g}^{-1}$, were somewhat deformed at the high scan rate of $1000 \mathrm{mV} \mathrm{s}^{-1}$ due to the existence of kinetic limitations for the transport of ions. Despite kinetic limitations at high scan rate, it should be noted that many other ACs previously tested as supercapacitor electrodes had much lower rate capabilities than CX2 $[6,26,52]$. However, the CV curve profile of MSP20X was rather rectangular, despite a much higher volume of narrow pores, $0.19 \mathrm{~cm}^{3} \mathrm{~g}^{-1}$, and a much lower volume of mesopores, $0.06 \mathrm{~cm}^{3}$ $\mathrm{g}^{-1}$. Such a difference can be explained by the much higher electrical conductivity of the MSP20X electrode, which should improve electron transfer and contribute to the high rate capability. 


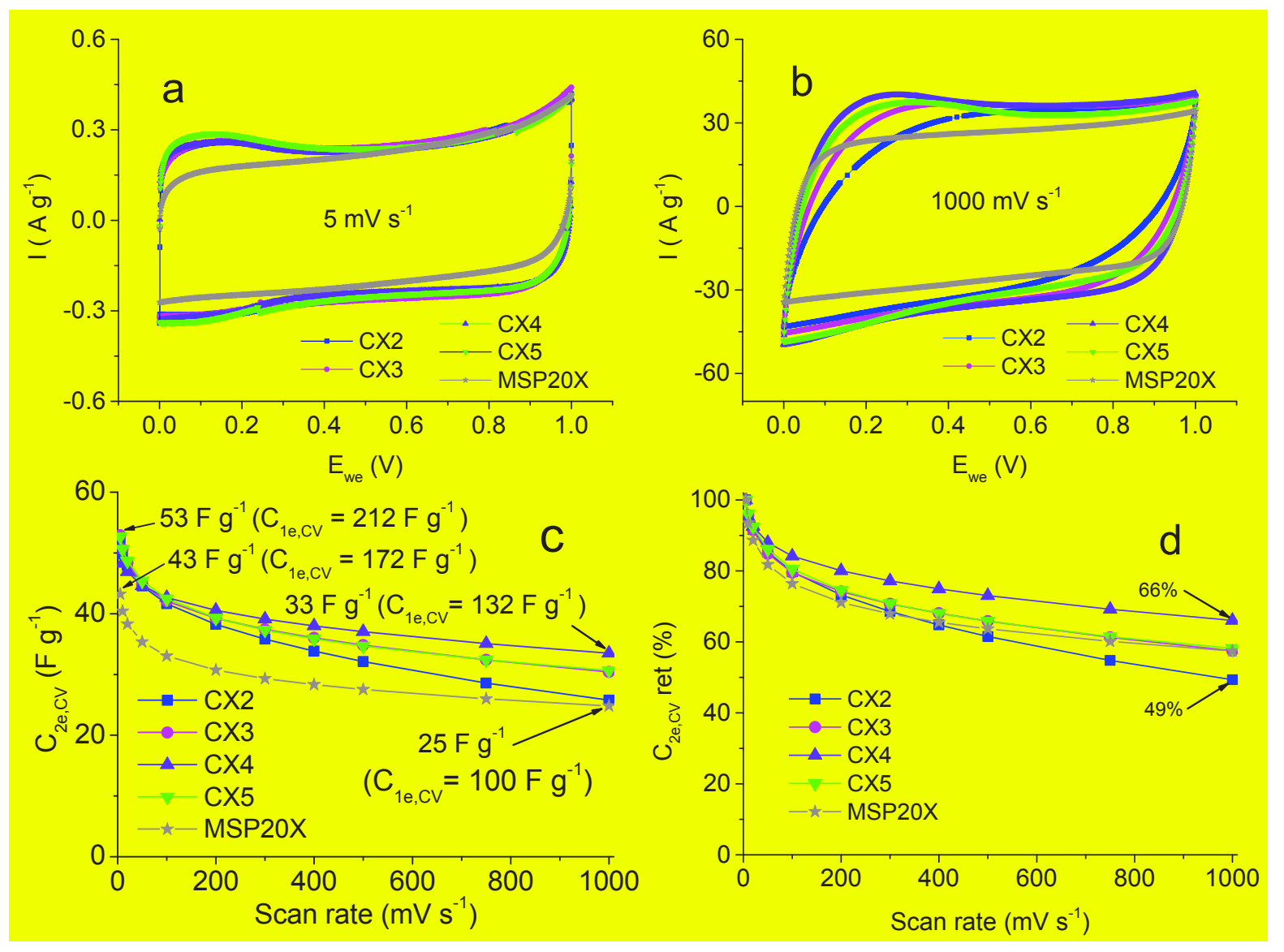

Figure 6. CV data of the materials obtained in a 2-electrode cell between scan rates of 5 and $1000 \mathrm{mV} \mathrm{s}^{-1}$ : a) CV curves at $5 \mathrm{mV} \mathrm{s}^{-1}$; b) CV curves at $1000 \mathrm{mV} \mathrm{s}^{-1}$; c) Gravimetric capacitance, $C_{2 e, G C D}$; d) Capacitance retention, $C_{2 e, G C D}$ ret.

From the CV tests, the PO-derived ACs gave higher capacitance values than MSP20X for the entire range of scan rates studied. The capacitance values of the former were similar at low scan rate, $\sim 53 \mathrm{~F} \mathrm{~g}^{-1}\left(C_{l e, C V}=212 \mathrm{~F} \mathrm{~g}^{-1}\right)$, while MSP20X only reached $43 \mathrm{~F} \mathrm{~g}^{-1}\left(C_{l e, C V}=172 \mathrm{~F} \mathrm{~g} \mathrm{~g}^{-1}\right)$ (Fig. 6c). CX4 provided the highest capacitance at the high scan rate of $1000 \mathrm{mV} \mathrm{s}^{-1}, 33 \mathrm{~F} \mathrm{~g}^{-1}$ $\left(C_{l e, C V}=132 \mathrm{~F} \mathrm{~g} \mathrm{~g}^{-1}\right)$, as well as the highest capacitance retention of all materials, $66.1 \%$ (Fig. 6c-d). These performances are consistent with those obtained with the GCD tests and, as explained above, are accounted for by the well-balanced volumes of micropores and mesopores 
of CX4. MSP20X had the lowest capacitance at $1000 \mathrm{mV} \mathrm{s}^{-1}, 25 \mathrm{~F} \mathrm{~g}^{-1}\left(C_{l e, C V}=100 \mathrm{~F} \mathrm{~g}^{-1}\right)$, and slightly lower capacitance retention than CX3 and CX5, 57.4\%. Finally, CX2 had the lowest capacitance retention, $49.3 \%$, consistent with the kinetic limitations and hindered ion transport at $1000 \mathrm{mV} \mathrm{s}^{-1}$.

The MSP20X electrode exhibited a faster frequency response than the ACs derived from PO, $0.28 \mathrm{~s}$, in agreement with its higher electrical conductivity (Fig. S12 in the Supporting Information). Since the PO-derived ACs showed similar electrical conductivities, porosity is the main factor explaining their frequency responses: the higher the mesopore volume of the carbons, the faster the frequency response due to an enhanced ion transport towards micropores [21]. As a result, CX2 had the slowest frequency response of $1.29 \mathrm{~s}$ while CX4 had the fastest one, $0.45 \mathrm{~s}$. Since frequency responses of less than $10 \mathrm{~s}$ are required for practical devices, the PO-derived ACs are appropriate materials for SCs.

Given the electrochemical performances of the PO-derived ACs, CX4 was the most appropriate material for actual devices because of its high capacitance retention and its high energy and power densities under high current regimes, high cycling stability up to 10000 charge-discharge cycles, high rate capability under high scan rate regimes, and fast frequency response. In addition, the use of the PO-derived ACs as supercapacitor electrodes allows revaluating these low-value coal tar-derived liquids, which in turn contributes to increase the viability of the European coal tar distillation plants. This is a novel approach to the synthesis of carbon gels, since it takes advantage of all the components of phenolic oils as precursors rather than just their phenolic fraction. 


\section{Conclusion}

ACs were successfully prepared for the first time by base-catalysed sol-gel polymerisation from phenolic oils (POs), and were subsequently applied as supercapacitor electrodes. This is a novel approach to the synthesis of carbon gels, since it takes advantage of all the major components of POs rather than the pure, single-component phenolic precursors that are normally used in sol-gel routes. This study provides a mean to promote these low-value coal tar liquids, thus contributing to increase the competitively of European coal tar distillation plants.

The electrochemical performances of the final ACs were higher than those of carbon gels previously obtained from classic precursors, and also than those of the commercial AC used for comparison, mainly due to the high mesopore volumes of the PO-derived ACs. The AC possessing the most developed microporosity, CX3, exhibited the highest volumetric capacitance, but mesoporosity was essential for obtaining the highest electrochemical performances under high current and scan rate regimes: mesopores facilitated the access of the aqueous electrolyte to the electroactive surface groups and promoted ion transport towards micropores. The higher the mesopore volume of the ACs, the lower the inner resistance, the faster the frequency response and the higher the cycling life of the devices.

Thanks to its well-balanced volumes of micropores and mesopores, CX4 was the most appropriate material for actual devices because of its high capacitance retention and its high energy and power densities under high current densities, high cycling stability up to 10000 charge-discharge cycles, high rate capability under high scan rate regimes, and fast frequency response. 
ASSOCIATED CONTENT

\section{Supporting Information.}

\section{FIGURES:}

Figure S1. (a) Nitrogen adsorption (full symbols) - desorption (empty symbols) isotherms, and (b) corresponding PSDs of the carbon materials.

Figure S2. C1s and O1s high-resolution spectra of the commercial AC, the MSP20X.

Figure S3. High-resolution XPS spectra of the PO-derived carbon materials: C1s (left) and O1s (right).

Figure S4. SEM images and EDX results taken on several points of the CX0 surface.

Figure S5. Chemical map of the CX0 surface obtained by SEM-EDX.

Figure S6. XRD pattern of CX0. The only crystalline phase corresponds to the fibre-like particles.

Figure S7. FT-IR spectra and main peaks of the components of the CX4 electrode: CX4 activated carbon, PTFE used as binder, and carbon black.

Figure S8. Contact angle of $2 \mathrm{~mol} \mathrm{~L}^{-1} \mathrm{H}_{2} \mathrm{SO}_{4}$ on CX2- and MSP20X-based electrodes.

Figure S9. Electrical conductivity of the carbon electrodes.

Figure S10. GCD curves of the carbon electrodes.

Figure S11. Interfacial capacitance of the materials calculated as: a) $C_{2 e, G C D} / A_{B E T}$, and b) $C_{2 e, G C D} / S_{N L D F T}$; c) Relationship between the specific capacitance, $C_{2 e, G C D}$, and the surface oxygen content; d) Volumetric capacitance of the materials, $C_{2 e, G C D} / V_{\text {elec. }}$.

Figure S12. Bode plot obtained from EIS tests, showing the frequency response of the materials.

\section{TABLES:}


Table S1. Textural data of the carbon materials.

\section{AUTHOR INFORMATION}

\section{Corresponding Author}

*A. Sanchez-Sanchez: angela.sanchez-sanchez@univ-lorraine.fr

*Vanessa Fierro: vanessa.fierro@univ-lorraine.fr

\section{Author Contributions}

The manuscript was written through contributions of all authors. All authors have given approval to the final version of the manuscript.

\section{ACKNOWLEDGMENT}

The IJL research team gratefully acknowledges the financial support of PROMOTEE 2016-2020, “Functional Porous Carbon Materials Derived from Coal Tar for Energy and Environmental Applications”, through the funds of the European Commission and the Research Fund for Coal \& Steel. Dr. A. Sanchez-Sanchez acknowledges the CNRS for financing her post-Doctoral contract.

\section{REFERENCES}

[1] Barnett E de B. Coal tar dyes and intermediates. London: Baillière, Tindall and Cox; 1919.

[2] Zander M. Aspects of Coal Tar Chemistry/A Review. Polycyclic Aromatic Compounds 1995;7:209-21. https://doi.org/10.1080/10406639508009625.

[3] Schobert $\mathrm{HH}$, Song C. Chemicals and materials from coal in the 21st century. Fuel 2002;81:15-32. https://doi.org/10.1016/S0016-2361(00)00203-9.

[4] Lee M, Lee J, Park SY, Min B, Kim B, In I. Production of graphene oxide from pitch-based carbon fiber. Scientific Reports 2015;5. https://doi.org/10.1038/srep11707.

[5] Lee J, Kim J, Hyeon T. Recent Progress in the Synthesis of Porous Carbon Materials. Advanced Materials 2006;18:2073-94. https://doi.org/10.1002/adma.200501576. 
[6] Abioye AM, Ani FN. Recent development in the production of activated carbon electrodes from agricultural waste biomass for supercapacitors: A review. Renewable and Sustainable Energy Reviews 2015;52:1282-93. https://doi.org/10.1016/j.rser.2015.07.129.

[7] Predeanu G, Axinte SM, Drăgoescu MF, González Z, Álvarez P, Granda M, et al. Microwave heating as a novel route for obtaining carbon precursors from anthracene oil. Fuel Processing Technology 2019;192:250-7. https://doi.org/10.1016/j.fuproc.2019.04.034.

[8] Hao Z-Q, Cao J-P, Wu Y, Zhao X-Y, Zhou L, Fan X, et al. Preparation of porous carbons from waste sugar residue for high performance electric double-layer capacitor. Fuel Processing Technology 2017;162:45-54. https://doi.org/10.1016/j.fuproc.2017.03.031.

[9] Allahbakhsh A, Bahramian AR. Self-assembled and pyrolyzed carbon aerogels: an overview of their preparation mechanisms, properties and applications. Nanoscale 2015;7:14139-58. https://doi.org/10.1039/C5NR03855C.

[10] Al-Muhtaseb SA, Ritter JA. Preparation and Properties of Resorcinol-Formaldehyde Organic and Carbon Gels. Advanced Materials 2003;15:101-14. https://doi.org/10.1002/adma.200390020.

[11] Scherdel C, Reichenauer G. Carbon xerogels synthesized via phenol-formaldehyde gels. Microporous and Mesoporous Materials 2009;126:133-42. https://doi.org/10.1016/j.micromeso.2009.05.033.

[12] Zhu Y, Hu H, Li W-C, Zhang X. Cresol-formaldehyde based carbon aerogel as electrode material for electrochemical capacitor. Journal of Power Sources 2006;162:738-42. https://doi.org/10.1016/j.jpowsour.2006.06.049.

[13] Dong-hui L, Jie Z, Jun-he Y, Zi-jun H, Tong-qi L, Guo C, et al. Preparation and microstructure control of carbon aerogels produced using m-cresol mediated sol-gel polymerization of phenol and furfural. New Carbon Materials 2008;23:165-70. https://doi.org/10.1016/S1872-5805(08)60020-7.

[14] Cheng S, D’Cruz I, Yuan Z, Wang M, Anderson M, Leitch M, et al. Use of biocrude derived from woody biomass to substitute phenol at a high-substitution level for the production of biobased phenolic resol resins. Journal of Applied Polymer Science 2011;121:2743-51. https://doi.org/10.1002/app.33742.

[15] Zha J, Roggendorf H. Sol-gel science, the physics and chemistry of sol-gel processing, Ed. by C. J. Brinker and G. W. Scherer, Academic Press, Boston 1990, xiv, 908 pp., bound?ISBN 0-12-134970-5. Advanced Materials 1991;3:522-522. https://doi.org/10.1002/adma.19910031025.

[16] Fuhu L, Weidong C, Zengmin S, Yixian W, Yunfang L, Hui L. Activation of mesocarbon microbeads with different textures and their application for supercapacitor. Fuel Processing Technology 2010;91:17-24. https://doi.org/10.1016/j.fuproc.2009.08.020.

[17] Babeł K, Jurewicz K. Electrical capacitance of fibrous carbon composites in supercapacitors. Fuel Processing Technology 2002;77-78:181-9. https://doi.org/10.1016/S0378-3820(02)00070-X.

[18] Frackowiak E, Jurewicz K, Szostak K, Delpeux S, Béguin F. Nanotubular materials as electrodes for supercapacitors. Fuel Processing Technology 2002;77-78:213-9. https://doi.org/10.1016/S0378-3820(02)00078-4.

[19] Castro-Muñiz A, Lorenzo-Fierro S, Martínez-Alonso A, Tascón JMD, Fierro V, SuárezGarcía F, et al. Ordered mesoporous carbons obtained from low-value coal tar products for electrochemical energy storage and water remediation. Fuel Processing Technology 2019;196:106152. https://doi.org/10.1016/j.fuproc.2019.106152. 
[20] Béguin F, Presser V, Balducci A, Frackowiak E. Carbons and Electrolytes for Advanced Supercapacitors. Advanced Materials 2014;26:2219-51. https://doi.org/10.1002/adma.201304137.

[21] Fernández JA, Tennison S, Kozynchenko O, Rubiera F, Stoeckli F, Centeno TA. Effect of mesoporosity on specific capacitance of carbons. Carbon 2009;47:1598-604. https://doi.org/10.1016/j.carbon.2009.02.012.

[22] García-Díez E, Schaefer S, Sanchez-Sanchez A, Celzard A, Fierro V, Maroto-Valer MM, et al. Novel Porous Carbons Derived from Coal Tar Rejects: Assessment of the Role of Pore Texture in $\mathrm{CO}_{2}$ Capture under Realistic Postcombustion Operating Temperatures. ACS Applied Materials \& Interfaces 2019;11:36789-99. https://doi.org/10.1021/acsami.9b13247.

[23] Jagiello J, Olivier JP. 2D-NLDFT adsorption models for carbon slit-shaped pores with surface energetical heterogeneity and geometrical corrugation. Carbon 2013;55:70-80. https://doi.org/10.1016/j.carbon.2012.12.011.

[24] Verhoeven L, Lodewyckx P. In Comparison of Dubinin-Radushkevich Micropore Volumes Obtained from N2, CO2 and H2O-Adsorption Isotherms. Carbon, vol. 2001, American Carbon Society Lexington; 2001.

[25] Sanchez-Sanchez A, Izquierdo MT, Mathieu S, González-Álvarez J, Celzard A, Fierro V. Outstanding electrochemical performance of highly $\mathrm{N}$ - and O-doped carbons derived from pine tannin. Green Chemistry 2017;19:2653-65. https://doi.org/10.1039/C7GC00491E.

[26] Sanchez-Sanchez A, Izquierdo MT, Medjahdi G, Ghanbaja J, Celzard A, Fierro V. Ordered mesoporous carbons obtained by soft-templating of tannin in mild conditions. Microporous and Mesoporous Materials 2018;270:127-39. https://doi.org/10.1016/j.micromeso.2018.05.017.

[27] Dimitrov AS, Kralchevsky PA, Nikolov AD, Noshi H, Matsumoto M. Contact angle measurements with sessile drops and bubbles. Journal of Colloid and Interface Science 1991;145:279-82. https://doi.org/10.1016/0021-9797(91)90120-W.

[28] Stoller MD, Ruoff RS. Best practice methods for determining an electrode material's performance for ultracapacitors. Energy \& Environmental Science 2010;3:1294. https://doi.org/10.1039/c0ee00074d.

[29] Zhao S, Wu F, Yang L, Gao L, Burke AF. A measurement method for determination of dc internal resistance of batteries and supercapacitors. Electrochemistry Communications 2010;12:242-5. https://doi.org/10.1016/j.elecom.2009.12.004.

[30] Arenillas A, Menéndez JA, Reichenauer G, Celzard A, Fierro V, Maldonado Hodar FJ, et al. Organic and Carbon Gels Derived from Biosourced Polyphenols. Organic and Carbon Gels, Cham: Springer International Publishing; 2019, p. 27-85. https://doi.org/10.1007/9783-030-13897-4_2.

[31] Arenillas A, Menéndez JA, Reichenauer G, Celzard A, Fierro V, Maldonado Hodar FJ, et al. Properties of Carbon Aerogels and Their Organic Precursors. Organic and Carbon Gels, Cham: Springer International Publishing; 2019, p. 87-121. https://doi.org/10.1007/978-3030-13897-4_3.

[32] Kaneko K, Ishii C. Superhigh surface area determination of microporous solids. Colloids and Surfaces 1992;67:203-12. https://doi.org/10.1016/0166-6622(92)80299-H.

[33] Hsieh C-T, Teng H. Influence of oxygen treatment on electric double-layer capacitance of activated carbon fabrics. Carbon 2002;40:667-674. https://doi.org/10.1016/S00086223(01)00182-8. 
[34] Swiatkowski A, Pakula M, Biniak S, Walczyk M. Influence of the surface chemistry of modified activated carbon on its electrochemical behaviour in the presence of lead(II) ions. Carbon 2004;42:3057-69. https://doi.org/10.1016/j.carbon.2004.06.043.

[35] Ferrari AC, Robertson J. Interpretation of Raman spectra of disordered and amorphous carbon. Physical Review B 2000;61:14095. https://doi.org/10.1103/PhysRevB.61.14095.

[36] Ferrari AC. Raman spectroscopy of graphene and graphite: Disorder, electron-phonon coupling, doping and nonadiabatic effects. Solid State Communications 2007;143:47-57. https://doi.org/10.1016/j.ssc.2007.03.052.

[37] Bernard S, Beyssac O, Benzerara K, Findling N, Tzvetkov G, Brown GE. XANES, Raman and XRD study of anthracene-based cokes and saccharose-based chars submitted to hightemperature $\quad$ pyrolysis. Carbon 2010;48:2506-16. https://doi.org/10.1016/j.carbon.2010.03.024.

[38] Lillo-Rodenas MA, Cazorla-Amoros D, Linares-Solano A. Understanding chemical reactions between carbons and $\mathrm{NaOH}$ and $\mathrm{KOH}$ An insight into the chemical activation mechanism. Carbon 2003;41:267-75. https://doi.org/10.1016/S0008-6223(02)00279-8.

[39] Li H, Guo H, Huang K, Liu B, Zhang C, Chen X, et al. Carbon electrode with conductivity improvement using silver nanowires for high-performance supercapacitor. Applied Physics A 2018;124:763. https://doi.org/10.1007/s00339-018-2182-4.

[40] Inagaki M, Konno H, Tanaike O. Carbon materials for electrochemical capacitors. Journal of Power Sources 2010;195:7880-903. https://doi.org/10.1016/j.jpowsour.2010.06.036.

[41] Frackowiak E, Beguin F. Carbon materials for the electrochemical storage of energy in capacitors. Carbon 2001;39:937-950. https://doi.org/10.1016/S0008-6223(00)00183-4.

[42] Teng H, Chang Y-J, Hsieh C-T. Performance of electric double-layer capacitors using carbons prepared from phenol-formaldehyde resins by $\mathrm{KOH}$ etching. Carbon 2001;39:1981-7. https://doi.org/10.1016/S0008-6223(01)00027-6.

[43] Weng T-C, Teng H. Characterization of High Porosity Carbon Electrodes Derived from Mesophase Pitch for Electric Double-Layer Capacitors. Journal of The Electrochemical Society 2001;148:A368. https://doi.org/10.1149/1.1357171.

[44] Lin C. Correlation of Double-Layer Capacitance with the Pore Structure of Sol-Gel Derived Carbon Xerogels. Journal of The Electrochemical Society 1999;146:3639. https://doi.org/10.1149/1.1392526.

[45] Saliger R, Fischer U, Herta C, Fricke J. High surface area carbon aerogels for supercapacitors. Journal of Non-Crystalline Solids 1998;225:81-5. https://doi.org/10.1016/S0022-3093(98)00104-5.

[46] Kuwabara Y, Yano H, Kanematsu Y, Oda H. Control and behaviors of resorcinolacetaldehyde carbon cryogel porous structures as electrodes for electric double-layer capacitors. TANSO 2008;2008:263-7. https://doi.org/10.7209/tanso.2008.263.

[47] Yu M, Li J, Wang L. KOH-activated carbon aerogels derived from sodium carboxymethyl cellulose for high-performance supercapacitors and dye adsorption. Chemical Engineering Journal 2017;310:300-6. https://doi.org/10.1016/j.cej.2016.10.121.

[48] Lee YJ, Park S, Seo JG, Yoon JR, Yi J, Song IK. Nano-sized metal-doped carbon aerogel for pseudo-capacitive supercapacitor. Current Applied Physics 2011;11:631-5. https://doi.org/10.1016/j.cap.2010.10.016.

[49] Xu X, Zhou J, Nagaraju DH, Jiang L, Marinov VR, Lubineau G, et al. Flexible, Highly Graphitized Carbon Aerogels Based on Bacterial Cellulose/Lignin: Catalyst-Free Synthesis 
and its Application in Energy Storage Devices. Advanced Functional Materials 2015;25:3193-202. https://doi.org/10.1002/adfm.201500538.

[50] Wei X, Wan S, Gao S. Self-assembly-template engineering nitrogen-doped carbon aerogels for high-rate supercapacitors. Nano Energy 2016;28:206-15. https://doi.org/10.1016/j.nanoen.2016.08.023.

[51] Long C, Jiang L, Wu X, Jiang Y, Yang D, Wang C, et al. Facile synthesis of functionalized porous carbon with three-dimensional interconnected pore structure for high volumetric performance supercapacitors. Carbon 2015;93:412-20. https://doi.org/10.1016/j.carbon.2015.05.040.

[52] Zhang LL, Zhao XS. Carbon-based materials as supercapacitor electrodes. Chemical Society Reviews 2009;38:2520. https://doi.org/10.1039/b813846j.

[53] Wang Q, Yan J, Fan Z. Carbon materials for high volumetric performance supercapacitors: design, progress, challenges and opportunities. Energy \& Environmental Science 2016;9:729-62. https://doi.org/10.1039/C5EE03109E.

[54] Bo Z, Zhu W, Ma W, Wen Z, Shuai X, Chen J, et al. Vertically Oriented Graphene Bridging Active-Layer/Current-Collector Interface for Ultrahigh Rate Supercapacitors. Advanced Materials 2013;25:5799-806. https://doi.org/10.1002/adma.201301794.

[55] Xu P, Kang J, Choi J-B, Suhr J, Yu J, Li F, et al. Laminated Ultrathin Chemical Vapor Deposition Graphene Films Based Stretchable and Transparent High-Rate Supercapacitor. ACS Nano 2014;8:9437-45. https://doi.org/10.1021/nn503570j. 

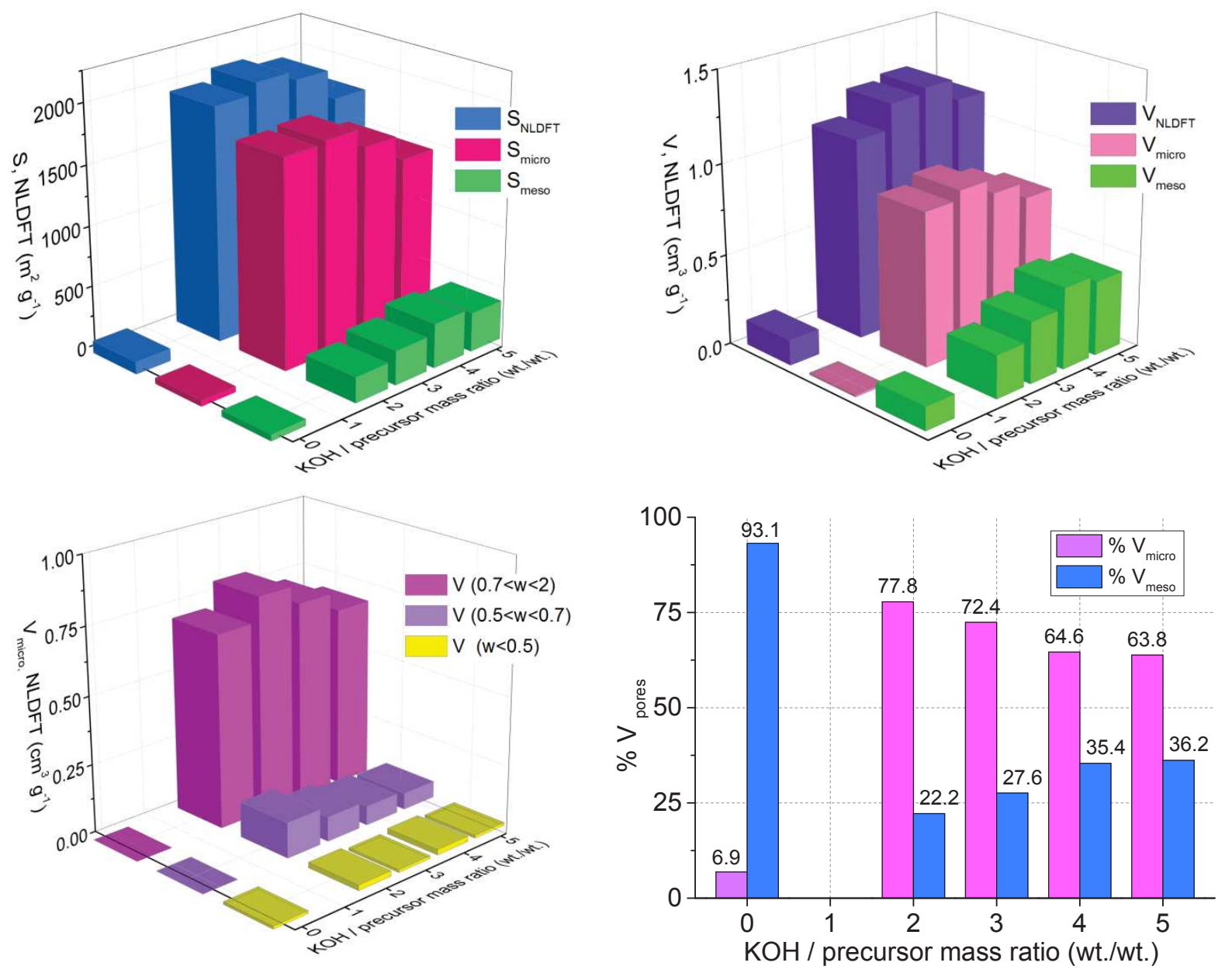

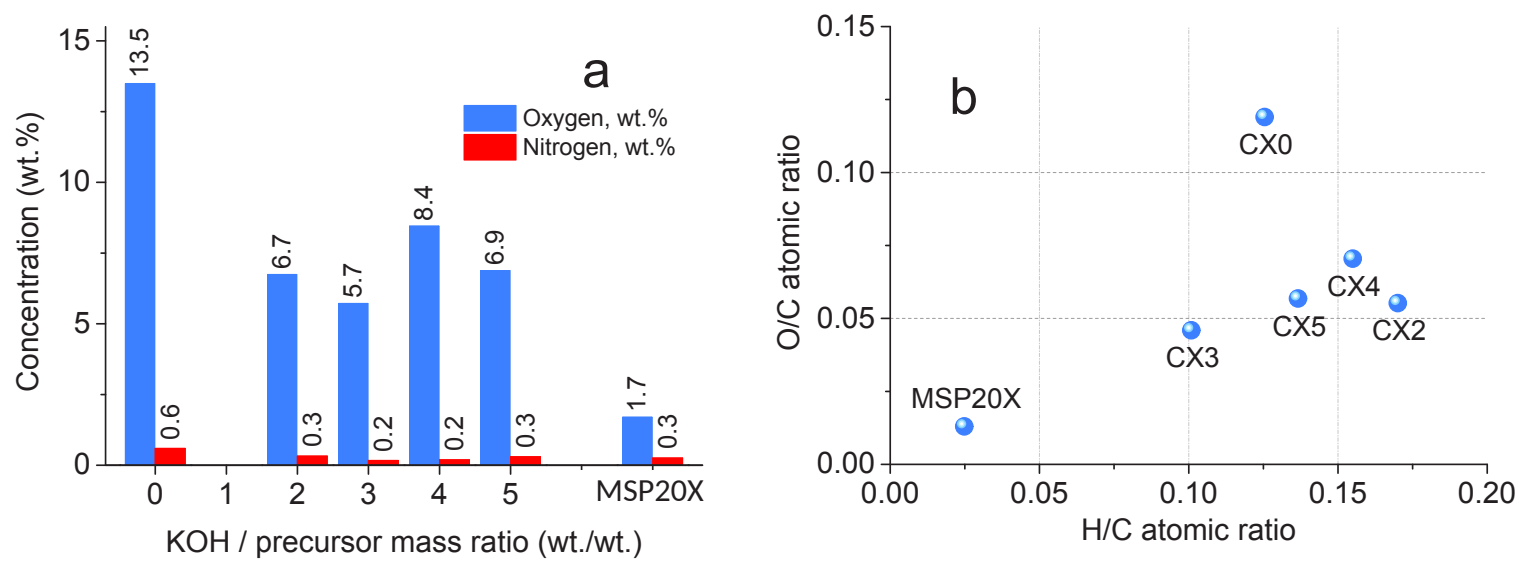


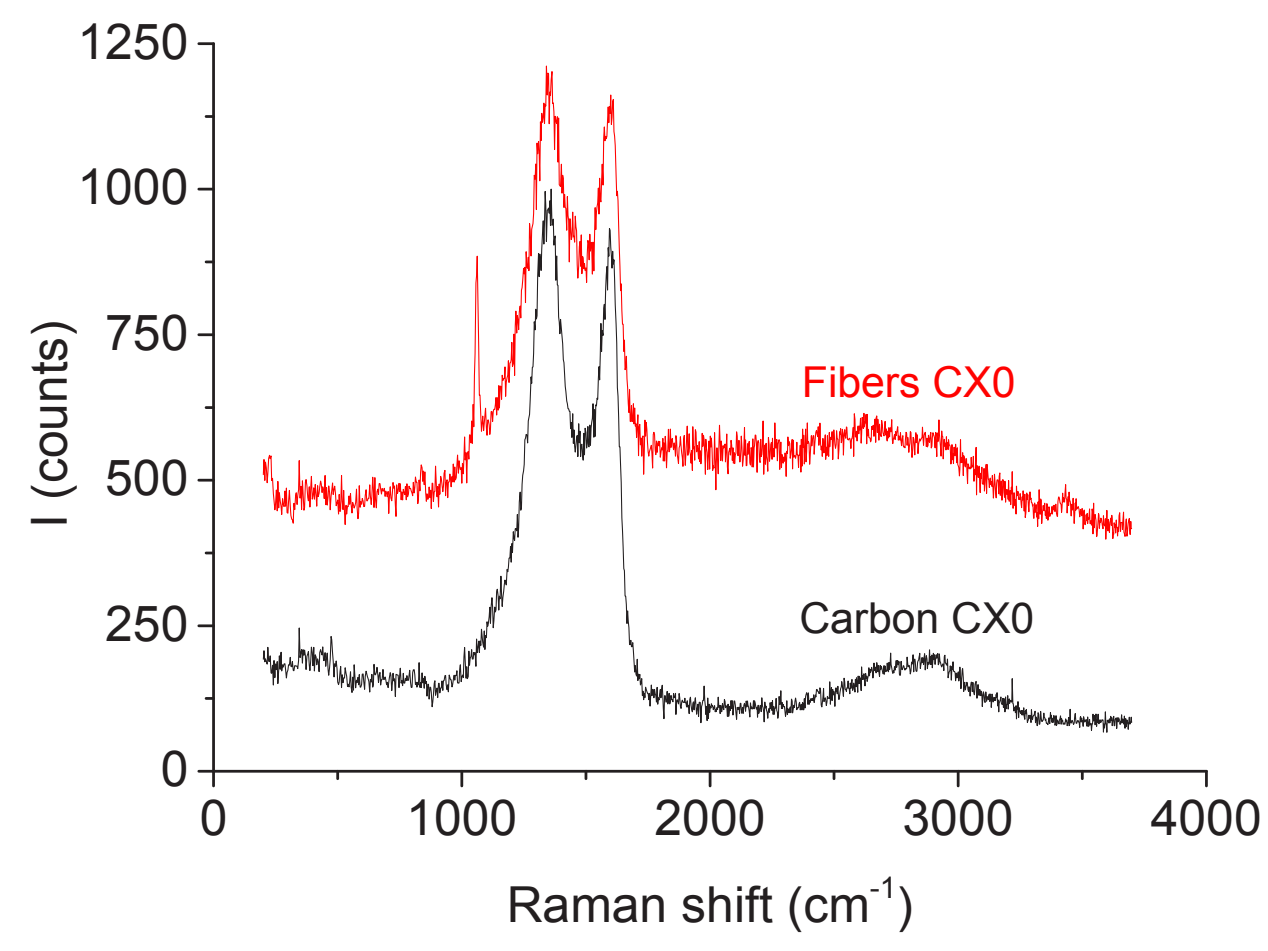



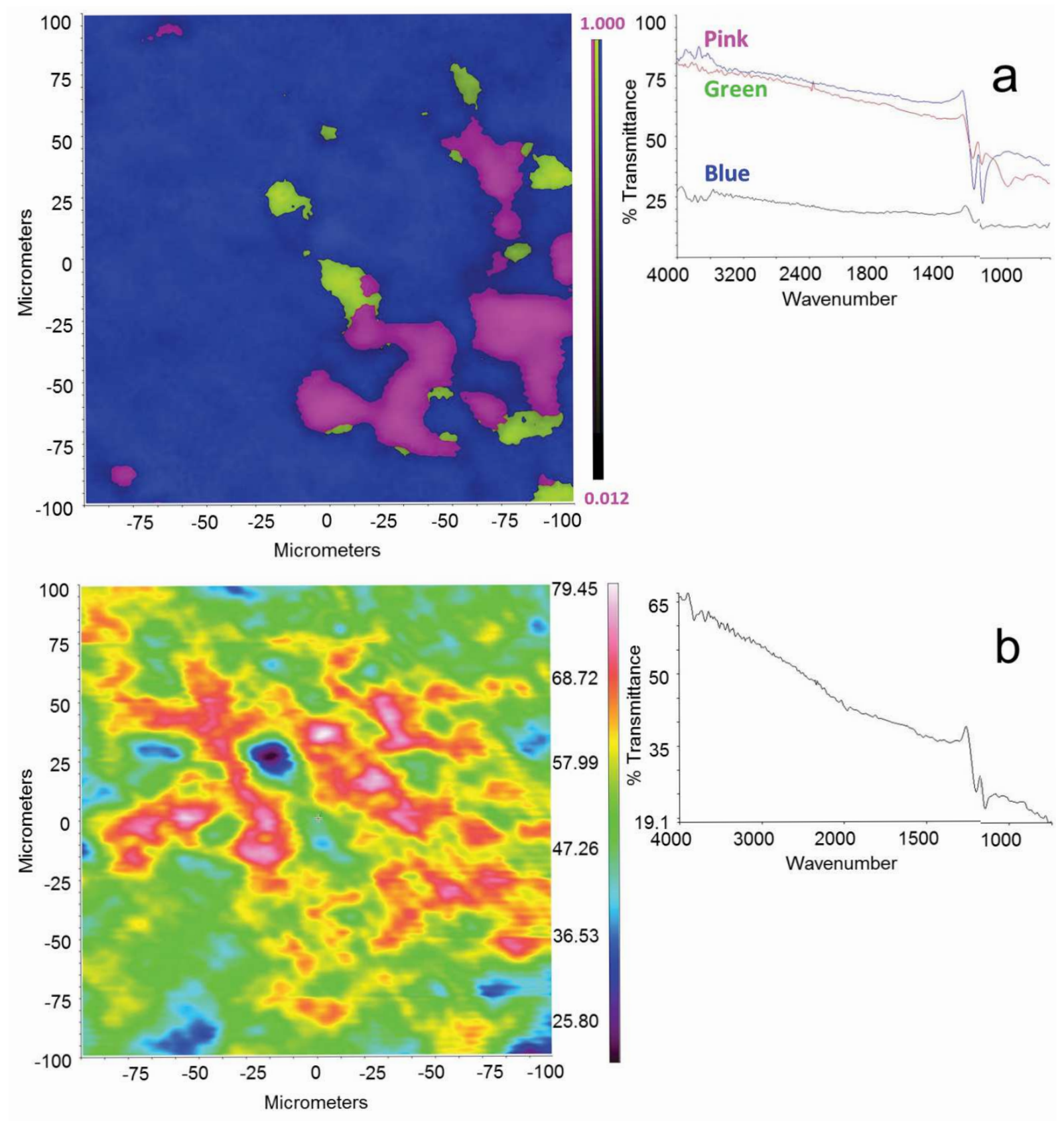

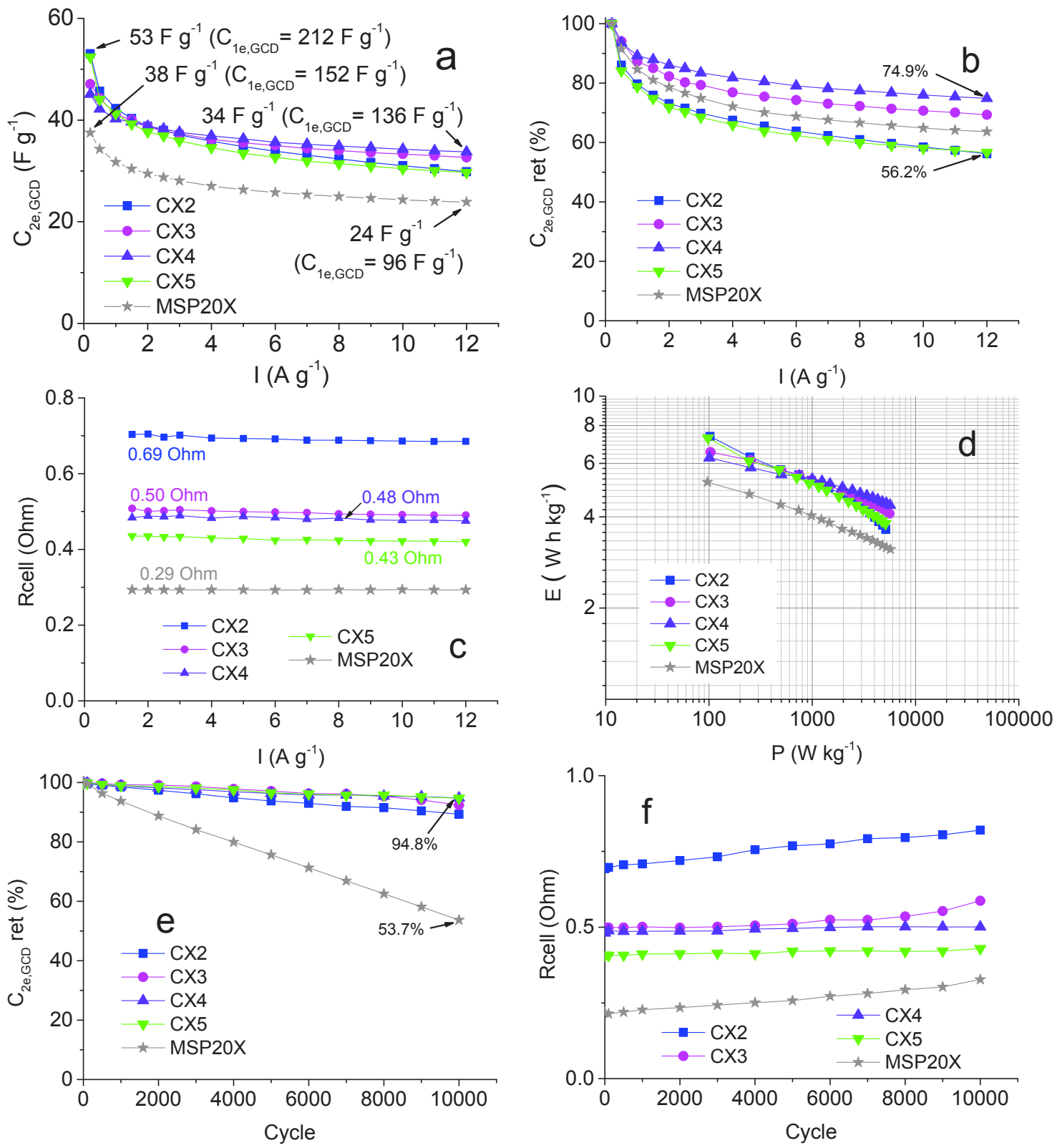

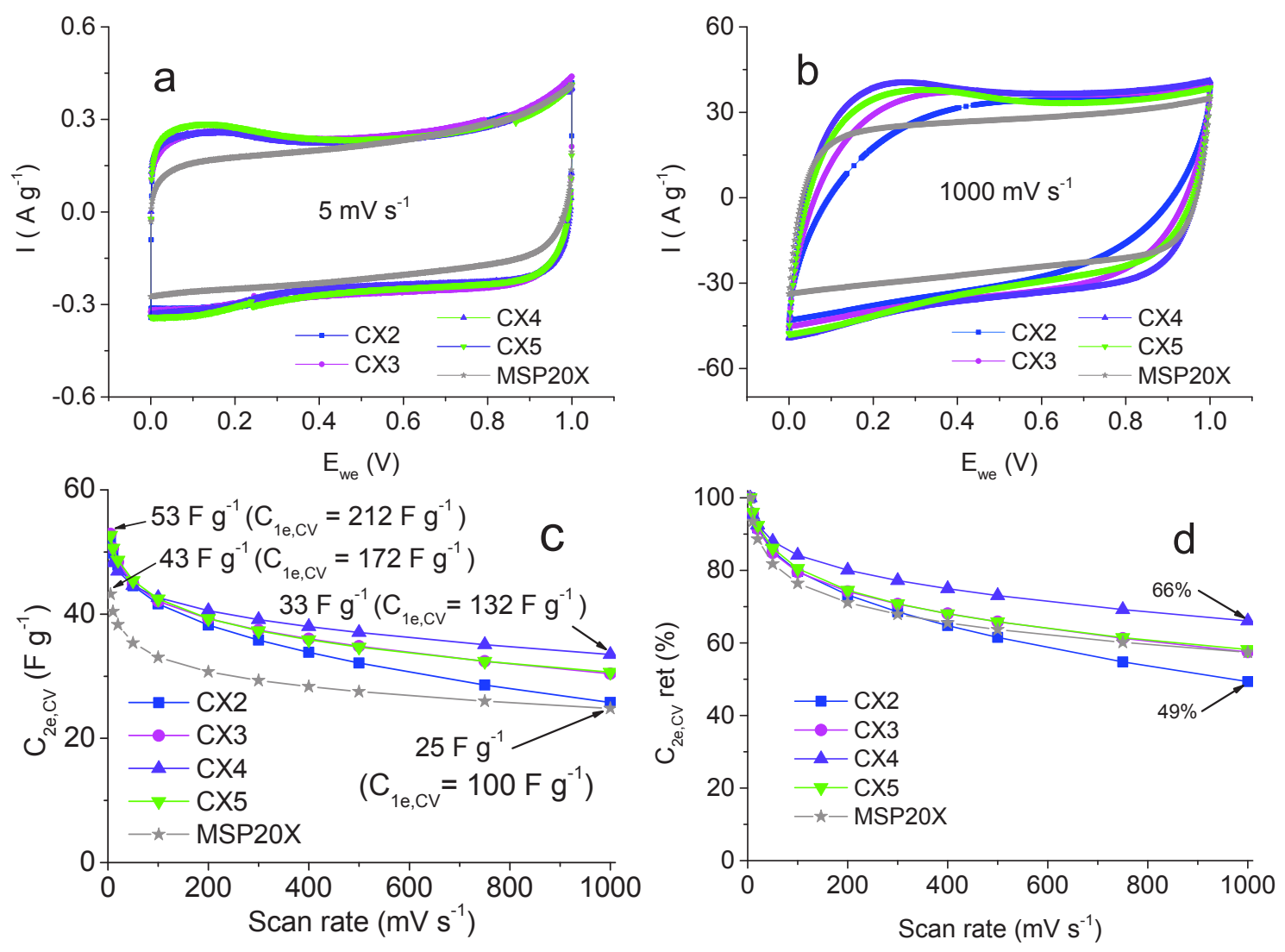
Table 1. Contributions to the C1s and O1s high-resolution spectra obtained by XPS.*

\begin{tabular}{|c|c|c|c|c|c|c|c|c|c|c|c|c|}
\hline \multirow[t]{2}{*}{ Sample } & \multicolumn{3}{|c|}{$\begin{array}{l}\text { Conc. } \\
\text { (at.\%) }\end{array}$} & \multicolumn{5}{|c|}{$\begin{array}{l}\text { C1s } \\
\text { BE (eV) } \\
\text { A (\%) }\end{array}$} & \multicolumn{4}{|c|}{$\begin{array}{l}\text { O1s } \\
\text { BE (eV) } \\
\mathrm{A}(\%)\end{array}$} \\
\hline & $\mathrm{C}$ & $\mathrm{O}$ & $\mathrm{N}$ & CI & CII & CIII & CIV & $\mathrm{CV}$ & OI & OII & OIII & O* \\
\hline $\mathrm{CX} 0 * *$ & 85.0 & $\begin{array}{l}10.7 \\
\end{array}$ & - & $\begin{array}{l}284.5 \\
63.7\end{array}$ & $\begin{array}{l}285.5 \\
28.1\end{array}$ & $\begin{array}{l}287.6 \\
3.9\end{array}$ & $\begin{array}{l}289.2 \\
1.8\end{array}$ & $\begin{array}{l}290.2 \\
2.4\end{array}$ & $\begin{array}{l}531.6 \\
32.0\end{array}$ & $\begin{array}{l}532.6 \\
41.0\end{array}$ & $\begin{array}{l}534.5 \\
11.1\end{array}$ & $\begin{array}{l}536.5 \\
15.9\end{array}$ \\
\hline CX2 & 95.2 & 4.8 & - & $\begin{array}{l}284.4 \\
62.6\end{array}$ & \begin{tabular}{l|l}
285.5 \\
27.8
\end{tabular} & $\begin{array}{l}287.6 \\
5.3\end{array}$ & $\begin{array}{l}289.2 \\
2.7\end{array}$ & $\begin{array}{l}290.4 \\
1.5\end{array}$ & $\begin{array}{l}531.1 \\
29.4\end{array}$ & $\begin{array}{l}532.8 \\
69.7\end{array}$ & $\begin{array}{l}535.1 \\
0.9\end{array}$ & - \\
\hline CX3 & 95.3 & 4.7 & - & $\begin{array}{l}284.4 \\
57.6\end{array}$ & $\begin{array}{l}285.5 \\
30.3\end{array}$ & $\begin{array}{l}287.6 \\
7.3\end{array}$ & $\begin{array}{l}289.2 \\
2.5\end{array}$ & $\begin{array}{l}290.4 \\
2.3\end{array}$ & $\begin{array}{l}531.1 \\
32.6\end{array}$ & $\begin{array}{l}532.8 \\
63.9\end{array}$ & $\begin{array}{l}534.5 \\
3.5\end{array}$ & - \\
\hline CX4 & 94.3 & 5.7 & - & $\begin{array}{l}284.4 \\
65.4\end{array}$ & $\begin{array}{l}285.5 \\
24.8\end{array}$ & $\begin{array}{l}287.6 \\
7.0\end{array}$ & $\begin{array}{l}289.1 \\
1.6\end{array}$ & $\begin{array}{l}290.2 \\
1.2\end{array}$ & $\begin{array}{l}531.3 \\
16.5\end{array}$ & $\begin{array}{l}532.8 \\
82.7\end{array}$ & $\begin{array}{l}534.5 \\
0.7\end{array}$ & - \\
\hline CX5 & 95.2 & 4.8 & - & $\begin{array}{l}284.4 \\
61.7\end{array}$ & $\begin{array}{l}285.5 \\
26.2\end{array}$ & $\begin{array}{l}287.6 \\
7.9\end{array}$ & $\begin{array}{l}289.2 \\
2.0\end{array}$ & $\begin{array}{l}290.3 \\
2.1\end{array}$ & $\begin{array}{l}531.3 \\
26.5\end{array}$ & $\begin{array}{l}532.8 \\
67.3\end{array}$ & $\begin{array}{l}535.1 \\
6.2\end{array}$ & - \\
\hline MSP20X & 95.2 & 4.7 & 0.12 & $\begin{array}{l}284.5 \\
60.9\end{array}$ & $\begin{array}{l}285.5 \\
24.9\end{array}$ & $\begin{array}{l}287.6 \\
7.5\end{array}$ & $\begin{array}{l}289.2 \\
3.5\end{array}$ & $\begin{array}{l}290.7 \\
3.1\end{array}$ & $\begin{array}{l}531.4 \\
22.7\end{array}$ & $\begin{array}{l}532.9 \\
73.2\end{array}$ & $\begin{array}{l}534.5 \\
4.1\end{array}$ & - \\
\hline
\end{tabular}

*CI: hydrocarbons, aromatics and aliphatics; CII: $\mathrm{Csp}^{3}$ and C-O single bonds associated with ethers, phenols and anhydrides; CIII: $\mathrm{C}=\mathrm{O}$ double bonds in carbonyls and quinones; CIV: C-O single bonds in carboxyls; CV: plasmon losses or shake-up $\pi-\pi$ satellites. OI: $\mathrm{C}=\mathrm{O}$ double bonds in quinone-type groups, carbonyls and carboxylic acids; $\mathrm{OII}$ : $-\mathrm{OH}$ bonds in phenols, $\mathrm{C}-\mathrm{O}-\mathrm{C}$ ether groups and $\mathrm{C}=\mathrm{O}$ bonds in ester and anhydride groups; OIII: single $\mathrm{C}-\mathrm{O}$ bonds in esters and anhydrides, $\mathrm{C}-\mathrm{O}$ bonds in carboxylic groups; $\mathrm{O}^{*}$ : chemisorbed oxygen and/or water [25]. BE (eV) and A (\%) stand for binding energy and relative contribution based on peak area, respectively.**Other elements were detected on the surface of CX0: 1.3 wt.\% Na, 0.4 wt.\% F, 0.5 wt.\% K and 2.0 wt.\% Cl. 


\section{Declaration of interests}

$\square$ The authors declare that they have no known competing financial interests or personal relationships that could have appeared to influence the work reported in this paper.

$\square$ The authors declare the following financial interests/personal relationships which may be considered as potential competing interests: 


\section{Activated carbon xerogels derived from phenolic oil: basic catalysis synthesis and electrochemical performances}

Angela Sanchez-Sanchez ${ }^{a, *}$, Maria Teresa Izquierdo ${ }^{b}$, Sandrine Mathieu ${ }^{c}$, Ghouti Medjahdi $^{c}$, Vanessa Fierro ${ }^{a} *$ and Alain Celzard ${ }^{a}$

a Université de Lorraine, CNRS, IJL, F-88000 Epinal, France.

b Instituto de Carboquimica, ICB-CSIC, Miguel Luesma Castan, 4, 50018 Zaragoza, Spain.

c Université de Lorraine, CNRS, IJL, F-54000 Nancy, France.

E-mail: *A. Sanchez-Sanchez: angela.sanchez-sanchez@univ-lorraine.fr. *Vanessa Fierro: vanessa.fierro@univ-lorraine.fr

Keywords: Phenolic oil, xerogel, sol-gel polymerisation, activated carbon, supercapacitor. 

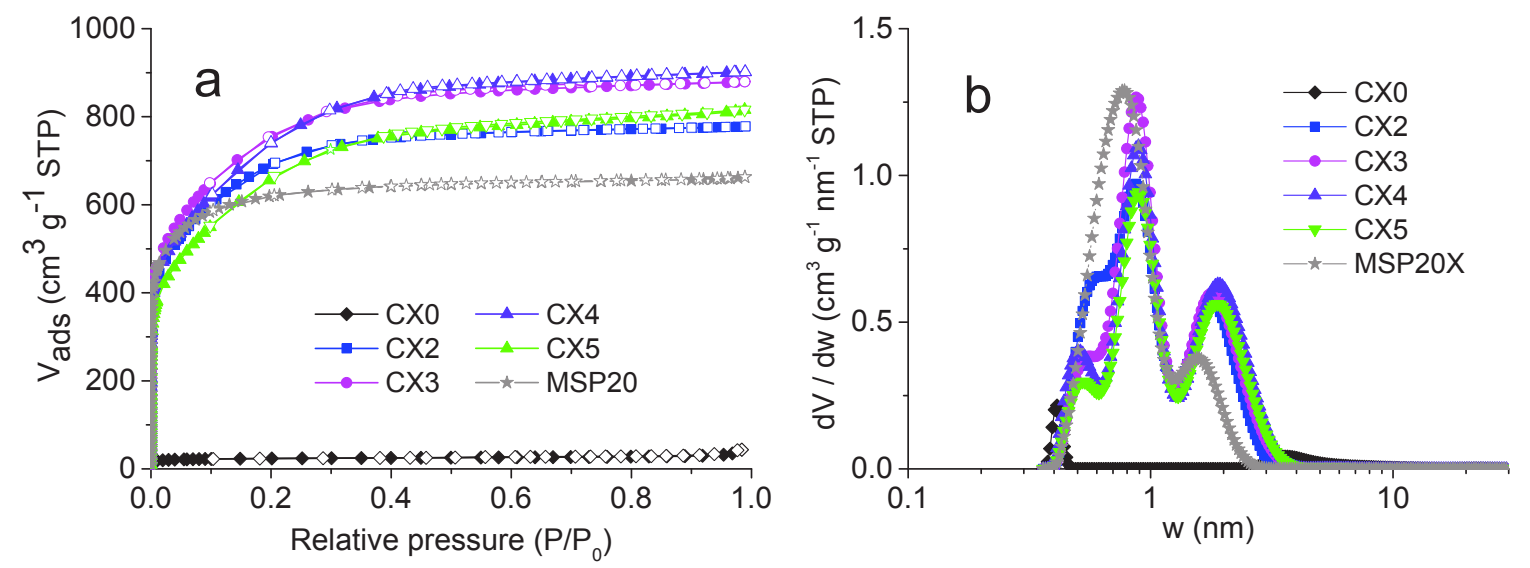

Figure S1. (a) Nitrogen adsorption (full symbols) - desorption (empty symbols) isotherms, and (b) corresponding PSDs of the carbon materials.
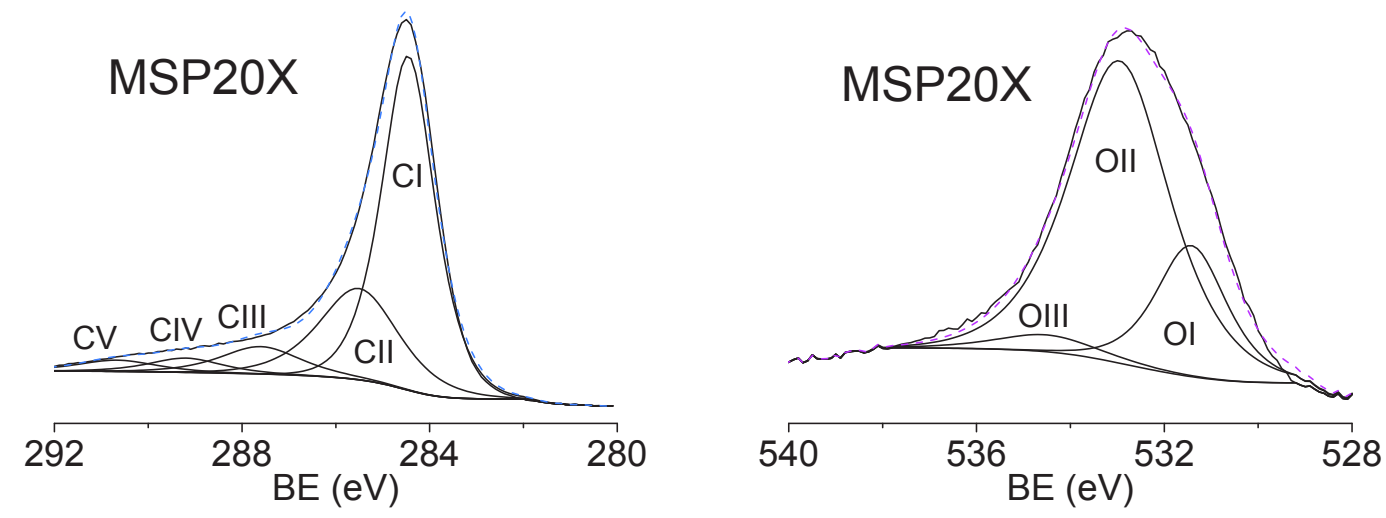

Figure S2. C1s and O1s high-resolution spectra of the commercial AC, the MSP20X. 


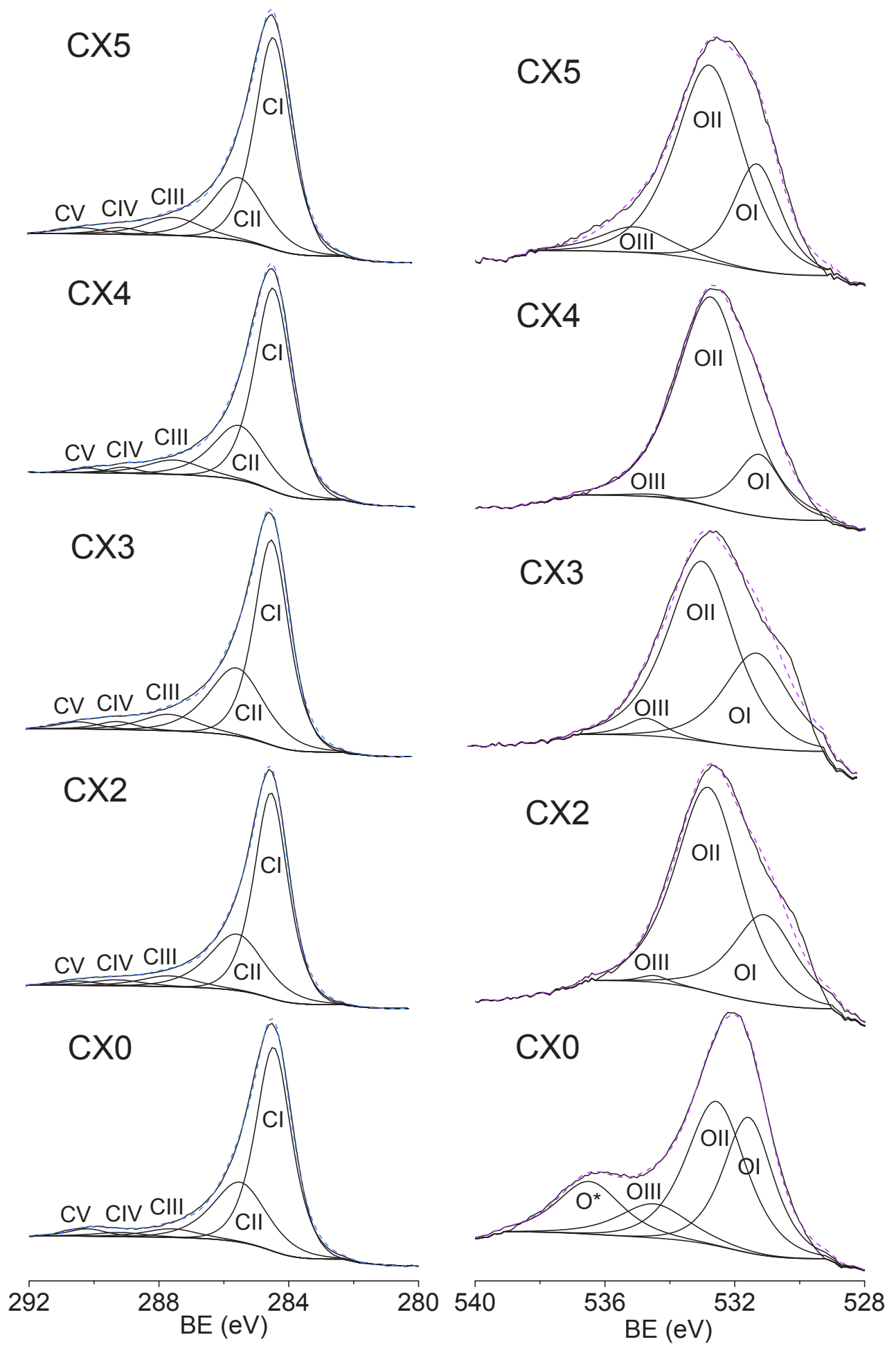

Figure S3. High-resolution XPS spectra of the PO-derived carbon materials: C1s (left) and O1s (right). 

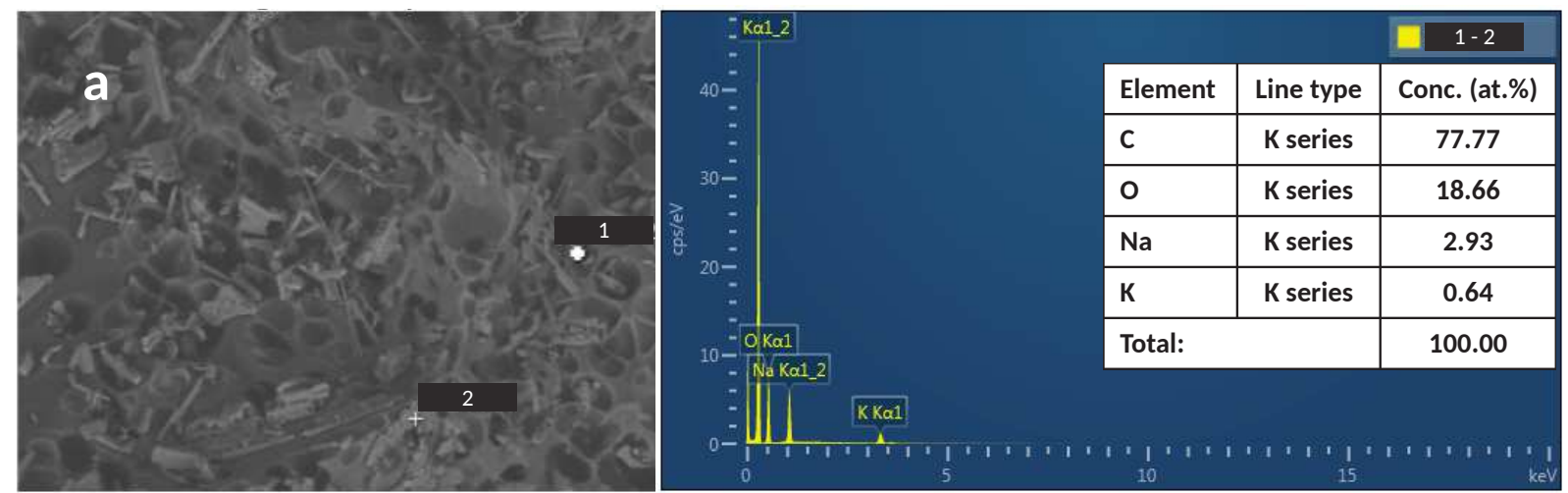

$\longdiv { 1 0 0 \mu \mathrm { m } }$
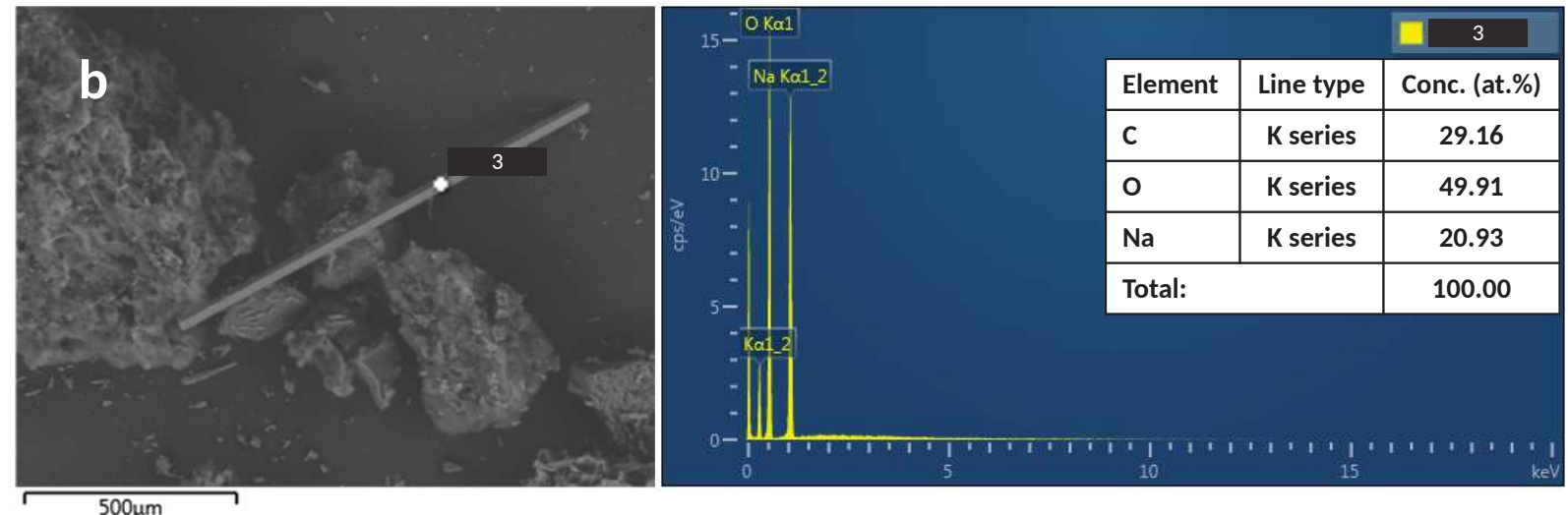

$500 \mu \mathrm{m}$

Figure S4. SEM images and EDX results taken on several points of the CX0 surface. 
$\mathrm{CK} \alpha 12$

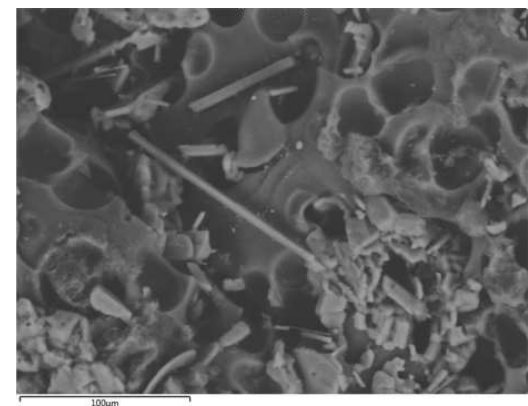

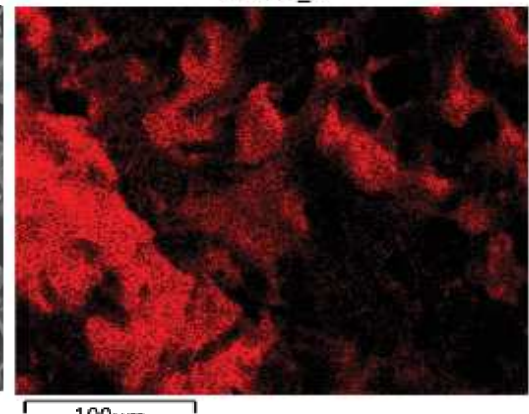

Na K $\alpha 12$

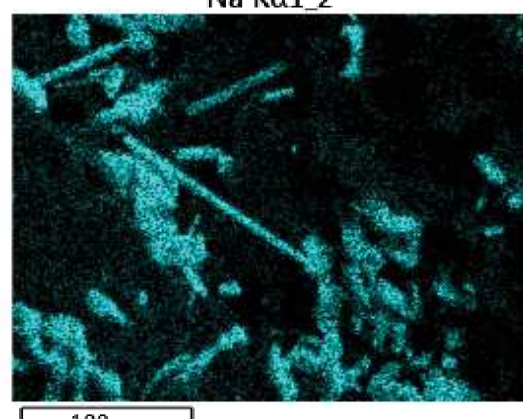

S K $\alpha 1$

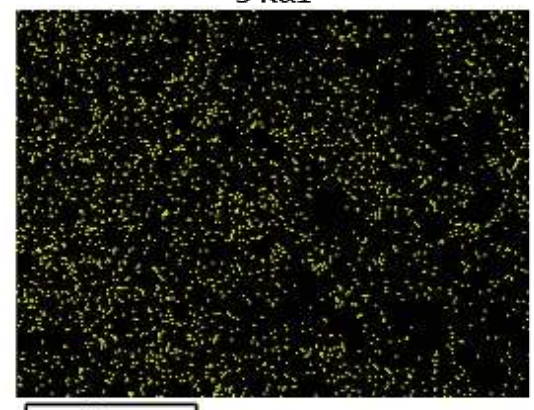

$100 \mu \mathrm{m}$
$\mathrm{O} K \alpha 1$

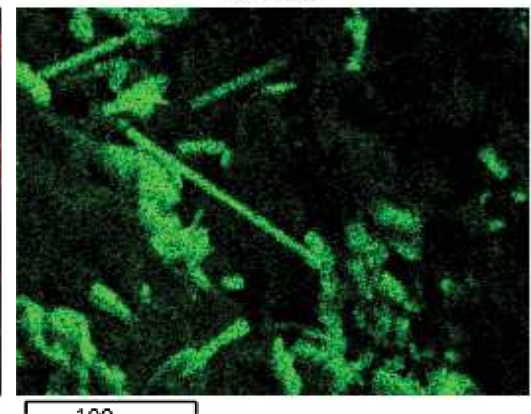

Si Ko1

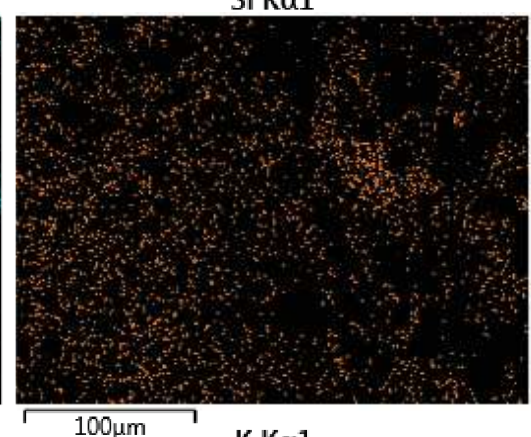

K Ka1

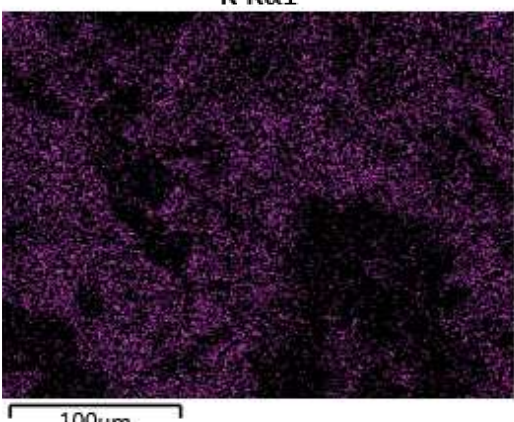

$100 \mu \mathrm{m}$

Figure S5. Chemical map of the CX0 surface obtained by SEM-EDX. 


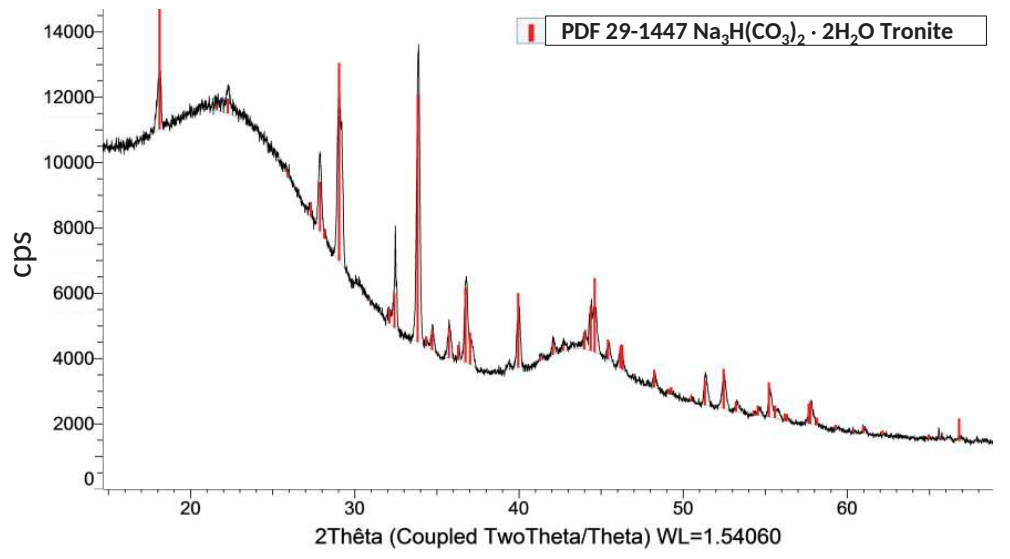

Figure S6. XRD pattern of CX0. The only crystalline phase corresponds to the fibre-like particles.

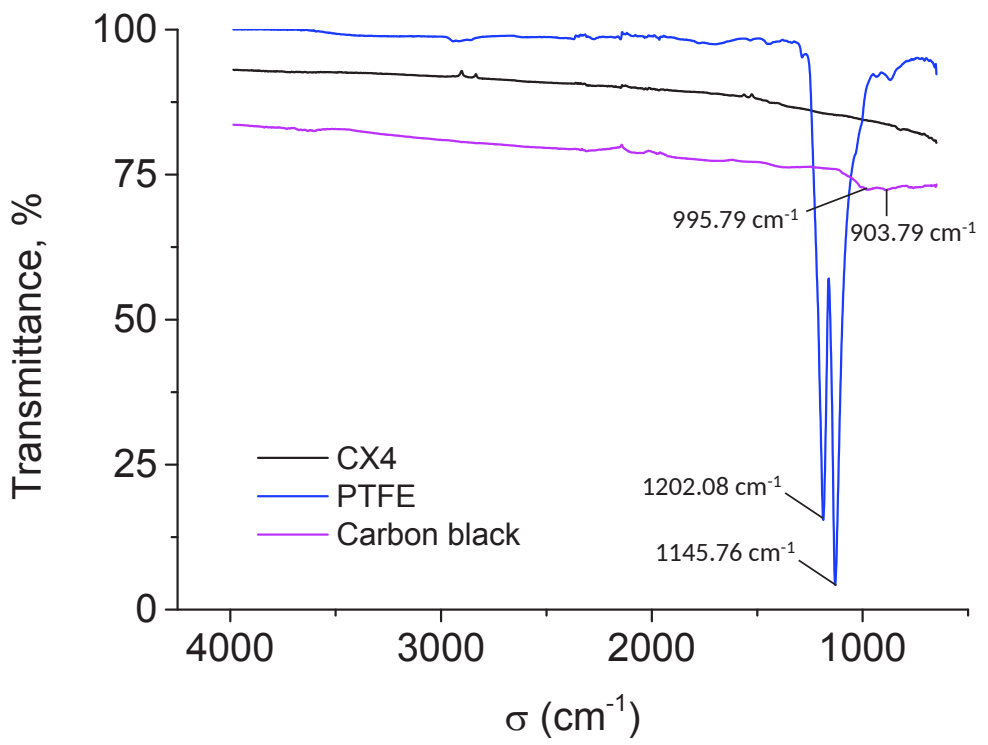

Figure S7. FT-IR spectra and main peaks of the components of the CX4 electrode: CX4 activated carbon, PTFE used as binder, and carbon black. 


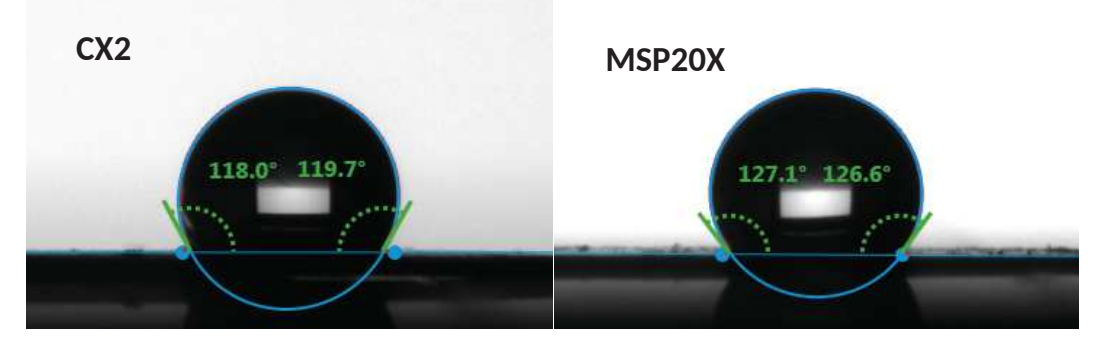

Figure S8. Contact angle of $2 \mathrm{~mol} \mathrm{~L}^{-1} \mathrm{H}_{2} \mathrm{SO}_{4}$ on CX2- and MSP20X-based electrodes.

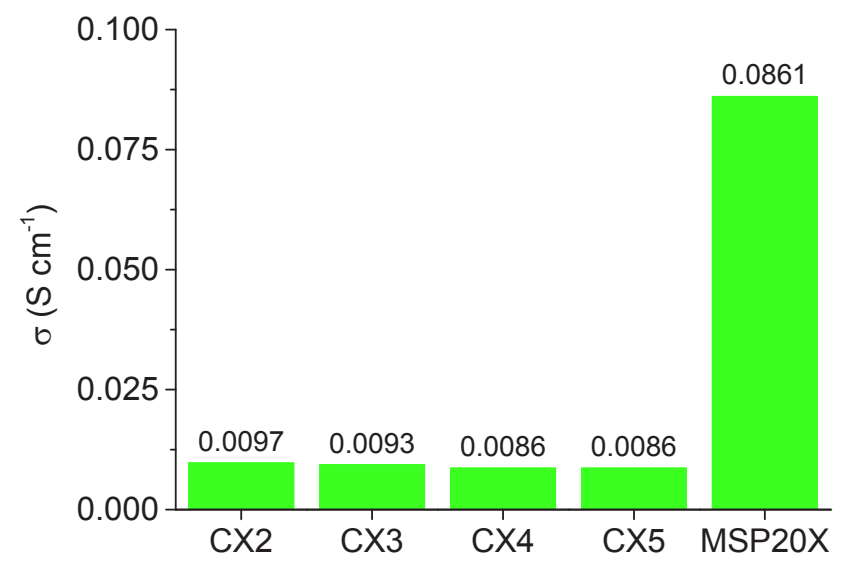

Figure S9. Electrical conductivity of the carbon electrodes.

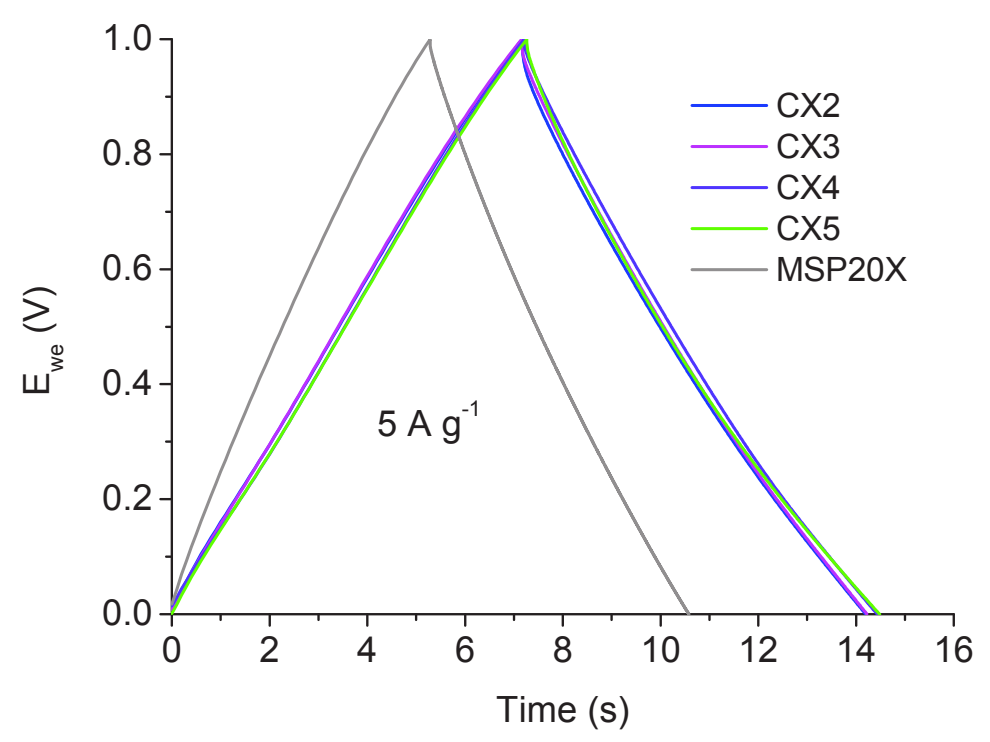

Figure S10. GCD curves of the carbon electrodes. 

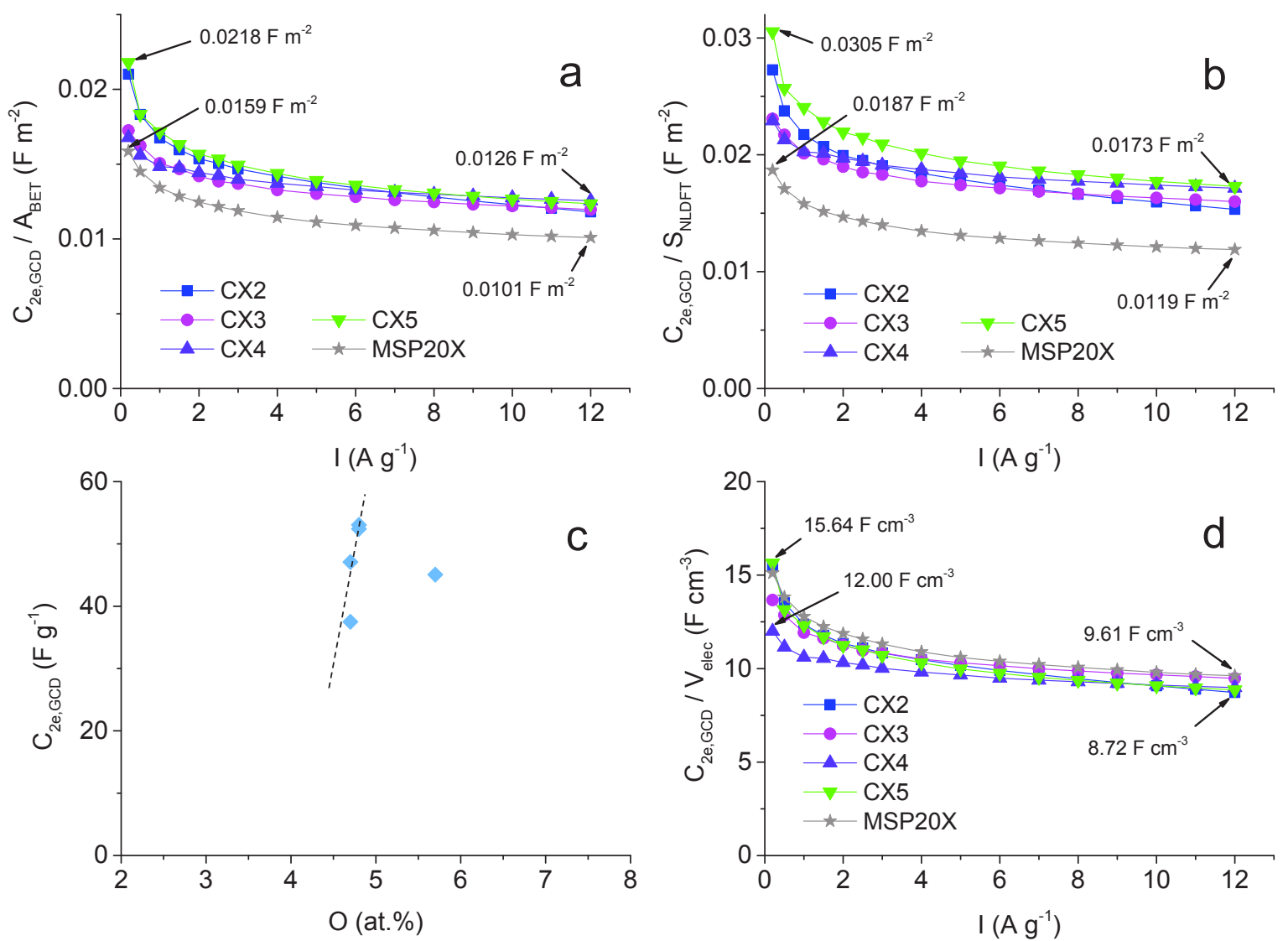

Figure S11. Interfacial capacitance of the materials calculated as: a) $C_{2 e, G C D} / A_{B E T}$, and b) $C_{2 e, G C D} / S_{N L D F T} ;$ c) Relationship between the specific capacitance, $C_{2 e, G C D}$, and the surface oxygen content; d) Volumetric capacitance of the materials, $C_{2 e, G C D} / V_{\text {elec }}$. 


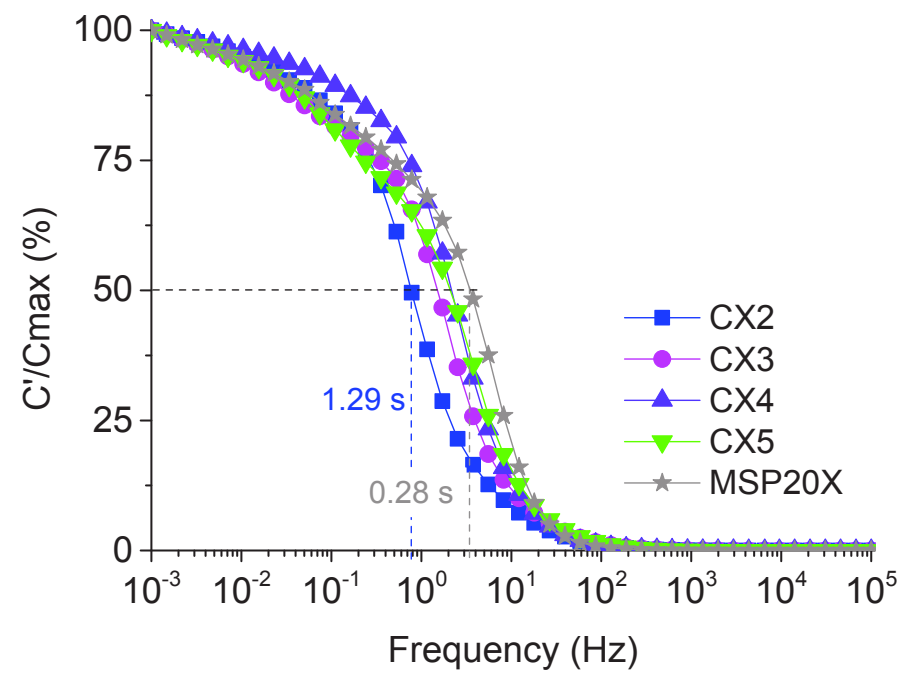

Figure S12. Bode plot obtained from EIS tests, showing the frequency response of the materials. 
Table S1. Textural data of the carbon materials.*

\begin{tabular}{|l|cccc|cccccccccccc|}
\hline \multirow{3}{*}{ Sample } & \multicolumn{10}{|c|}{ Data from nitrogen and carbon dioxide isotherms } \\
\cline { 2 - 6 } & $A_{B E T}$ & $V_{T}$ & $V_{\mu-N 2}$ & $V_{\mu-C O 2}$ & $S_{N L D F T}$ & $S_{\text {micro }}$ & $S_{\text {meso }}$ & $V_{N L D F T}$ & $V_{w<0.5}$ & $V_{0.5<w<0.7}$ & $V_{0.7<w<2}$ & $V_{\text {micro }}$ & $V_{\text {meso }}$ & $\% V_{\text {micro }}$ & $\% \mathrm{~V}_{\text {meso }}$ & $w_{0}(d V)$ \\
\hline CX0 & 91 & 0.05 & 0.04 & 0.07 & 102 & 48 & 53 & 0.14 & 0.01 & 0.00 & 0.00 & 0.01 & 0.13 & 6.9 & 93.1 & 0.42 \\
\hline CX2 & 2525 & 1.20 & 0.82 & 0.39 & 1946 & 1734 & 212 & 1.10 & 0.02 & 0.13 & 0.71 & 0.86 & 0.24 & 77.8 & 22.2 & 1.17 \\
CX3 & 2729 & 1.36 & 0.90 & 0.44 & 2041 & 1757 & 284 & 1.24 & 0.01 & 0.09 & 0.80 & 0.90 & 0.34 & 72.4 & 27.6 & 1.19 \\
CX4 & 2687 & 1.40 & 0.85 & 0.36 & 1968 & 1601 & 368 & 1.27 & 0.02 & 0.07 & 0.73 & 0.82 & 0.45 & 64.6 & 35.4 & 1.21 \\
CX5 & 2405 & 1.26 & 0.76 & 0.35 & 1717 & 1393 & 325 & 1.15 & 0.01 & 0.06 & 0.66 & 0.73 & 0.41 & 63.8 & 36.2 & 1.23 \\
\hline MSP20X & 2363 & 1.02 & 0.83 & 0.46 & 2007 & 1955 & 52 & 0.93 & 0.01 & 0.18 & 0.68 & 0.87 & 0.06 & 93.4 & 6.6 & 1.04 \\
\hline
\end{tabular}

$* A_{B E T}\left(\mathrm{~m}^{2} \mathrm{~g}^{-1}\right)$ : surface area calculated by applying the BET equation to the $\mathrm{N}_{2}$ adsorption isotherms; $V_{T}\left(\mathrm{~cm}^{3} \mathrm{~g}^{-1}\right)$ : total pore volume at $\mathrm{P} / \mathrm{P}_{0}=0.976$; $V_{\mu-N 2}\left(\mathrm{~cm}^{3} \mathrm{~g}^{-1}\right)$ : micropore volume calculated by applying the Dubinin-Radushkevich (DR) equation to the $\mathrm{N}_{2}$ adsorption isotherms; $V_{\mu-C O 2}\left(\mathrm{~cm}^{3} \mathrm{~g}^{-1}\right)$ : ultramicropore volume determined by applying the Dubinin-Radushkevich (DR) equation to the $\mathrm{CO}_{2}$ isotherms. Textural parameters calculated by applying the 2D-NLDFT-HS model (SAIEUS software) to both the $\mathrm{CO}_{2}$ and $\mathrm{N}_{2}$ adsorption isotherms: $S_{N L D F T}\left(\mathrm{~m}^{2} \mathrm{~g}^{-1}\right)$ : surface area; $S_{\text {micro }}\left(\mathrm{m}^{2} \mathrm{~g}^{-1}\right)$ : micropore surface area; $S_{\text {meso }}\left(\mathrm{m}^{2} \mathrm{~g}^{-1}\right)$ : mesopore surface area; $V_{N L D F T}\left(\mathrm{~cm}^{3} \mathrm{~g}^{-1}\right)$ : cumulative pore volume; $V_{w<0.5}, V_{0.5<w<0.7}, V_{0.7<w<2}\left(\mathrm{~cm}^{3} \mathrm{~g}^{-1}\right):$ volume of micropores with sizes $<0.5,0.5<w<0.7$ and $0.7<w<2 \mathrm{~nm}$, respectively; $V_{\text {micro }}\left(\mathrm{cm}^{3} \mathrm{~g}^{-1}\right)$ : micropore volume; $V_{\text {meso }}\left(\mathrm{cm}^{3} \mathrm{~g}^{-1}\right)$ : mesopore volume calculated as the difference $V_{N L D F T}-V_{\text {micro }} ; \% V_{\text {micro }}(\%)=$ micropore fraction; $\% V_{\text {meso }}(\%)=$ mesopore fraction; $w_{0}(d V)(\mathrm{nm})$ : average micropore diameter. 